\title{
Does better accessibility help to reduce social exclusion? Evidence from the City of São Paulo, Brazil.
}

\author{
Gregório Luz ${ }^{1,2}$, Matheus H. C. Barboza ${ }^{3,4}$, Licinio Portugal ${ }^{1}$, Mariana \\ Giannotti $^{3}$, and Bert van Wee ${ }^{5}$
}

1. Transport Engineering Program, Alberto Luiz Coimbra Institute for Graduate Studies and Research in Engineering (COPPE), Federal University of Rio de Janeiro (UFRJ), Rio de Janeiro, Brazil,

2. Center for the Study of the Politics and Economics of the Public Sector, Getulio Vargas Foundation (CEPESP/FGV), São Paulo, Brazil

3. Polytechnic School, University of São Paulo (USP), São Paulo, Brazil

4. Department of Civil Engineering, University of Twente, the Netherlands

5. Transport and Logistics Group, Faculty Technology, Policy and Management, Delft University of Technology, Delft, the Netherlands

November, 2022

This is a preprint of the paper published at Transportation Research Part A: Policy and Practice, Volume 166, December 2022, Pages 186-217. DOI: https://doi.org/10.1016/i.tra.2022.10.005

\section{Please cite:}

Luz, G., Barboza, M. H. C., Portugal, L., Giannotti, M., van Wee, B. (2022). Does better accessibility help to reduce social exclusion? Evidence from the city of São Paulo, Brazil. Transportation Research Part A: Policy and Practice, 166, 186-217. https://doi.org/10.1016/j.tra.2022.10.005

\section{Highlights}

- A conceptual model of the causal relationship between accessibility, activity participation and transport-related social exclusion is provided.

- A systematic literature of available empirical evidence about the accessibility-activity participation relationship is conducted.

- A causal relationship between accessibility and activity participation levels in a Global South context (City of São Paulo) is presented.

- We contributes to the theoretical debate about the curve shape of the relationship between accessibility and activity participation

- The findings suggest that low accessibility levels may severely restrict individuals' life chances and shed light on the importance of including the accessibility dimension in transport policies. 


\section{Does better accessibility help to reduce social exclusion? Evidence from the City of São Paulo, Brazil.}

\section{Abstract}

Most transport equity and transport-related social exclusion (TRSE) studies assume that increasing accessibility levels lead to increased activity participation and, therefore, a reduction in social exclusion. Although this assumption makes sense from a theoretical point of view, this causal relationship has not yet been validated in practice. Previous studies investigating the accessibility-participation relationship were inconclusive, indicating that increasing accessibility has a limited impact on activity participation levels, if any. Moreover, the existing empirical evidence in the literature in the Global South context is scarce, is merely correlational and fails to infer causality between both variables. The contributions of the paper are threefold. First, (a) to provide a conceptual model of the causal relationship between accessibility, activity participation and risk of transport-related social exclusion (TRSE); second, (b) to summarise the available empirical evidence about the accessibility-activity participation relationship through a systematic literature review; and third, (c) to provide evidence of the causal relationship between accessibility and activity participation levels in a Global South context. Three Poisson regression models associated with an instrumental variable identification strategy were used to assess the causal effect between accessibility and participation in total, mandatory and discretionary activities in the city of São Paulo, Brazil. The three models showed a highly significant, strong correlation between an individual's accessibility level and their actual participation in total, mandatory and discretionary activities. Models that ignore the possible endogeneity present in the relationship between accessibility and activity participation may underestimate the effect of accessibility. Based on our results, we argue that low accessibility levels may severely restrict individuals' life chances and add evidence that accessibility has to be an important instrument to support transport policies' decision-making.

\section{Introduction}

The lack of access to critical opportunities in society is associated with substantial economic and social costs (United Nations, 2016). Studies on the relationship between accessibility and social issues date back 1970s (e.g. Wachs and Kumagai (1973); Black and Conroy (1977)). However, the 
Luz, G., Barboza, M. H. C., Portugal, L., Giannotti, M., van Wee, B. (2022). Does better accessibility help to reduce social exclusion? Evidence from the city of São Paulo, Brazil. Transportation Research Part A: Policy and Practice, 166, 186-217. https://doi.org/10.1016/i.tra.2022.10.005

interest in assessing transport investments and other policies from the perspective of accessibility has emerged only in the last two decades (Martens, 2016b). Currently, accessibility measures have been used to assess the distributional effects of transport policies and identify groups at risk of social exclusion (Páez et al., 2010; Curl et al., 2011; Boisjoly and El-Geneidy, 2017a; Allen and Farber, 2020). Accessibility is treated by transport-related social exclusion (TRSE) research as a key indicator for the number of opportunities available to individuals, where it is assumed that greater levels of accessibility lead to higher levels of participation and thus less social exclusion.

Despite the theoretical consistency of this statement, most of the accessibility measures used in practice to assess TRSE risk account only for some of the components (Kamruzzaman et al., 2016; Pyrialakou et al., 2016) that shape an individual's possibilities of participation and do not capture the complex social interactions, perceptions, and behaviours that influence activity participation (Bantis and Haworth, 2020; Luz and Portugal, 2021; Curl et al., 2011; Martens, 2016a). The empirical research that has tested the accessibility-activity participation relationship did not indicate a consensus regarding its validity. Some articles found that accessibility levels are associated with higher activity participation levels (Allen and Farber, 2020; Calvo et al., 2019; Merlin, 2015; Ding et al., 2016), while others found that this relationship is weak or not statistically significant (Kitamura et al., 1997; Ewing et al., 1996; Wang and Cao, 2017). Some papers found that this relationship may be valid for a specific type of activity, transport mode, or accessibility measure (Cordera et al., 2017; Thill and Kim, 2005; Masoumi, 2021; Zhang et al., 2019), and others, in contrast, attest that higher accessibility leads to lower activity participation (Williams, 1989; Wu et al., 2012; Lavieri et al., 2018). This lack of consensus may suggest that it is not sure that TRSE evaluations using accessibility measures produce reliable results.

To assess transport-related social exclusion, the distribution of accessibility among the population should be sufficient since we want to assess what people can potentially access and not necessarily the activities they accessed and participated in. People would not be considered socially excluded if they could participate in desired activities but did not do so, since they have the freedom of choice. In this sense, we could restrict our analysis to accessibility distribution if we were sure that the chosen accessibility measure represents an individual's participation possibilities.

However, as previously mentioned, the currently existing accessibility measures cannot capture all the factors influencing an individual's ability to participate in activities. Because of this, it is also necessary to assess the number of activities that individuals have participated in to ensure 
Luz, G., Barboza, M. H. C., Portugal, L., Giannotti, M., van Wee, B. (2022). Does better accessibility help to reduce social exclusion? Evidence from the city of São Paulo, Brazil. Transportation Research Part A: Policy and Practice, 166, 186-217. https://doi.org/10.1016/i.tra.2022.10.005

that the chosen accessibility measure is appropriate to guide transportation policies aimed at reducing social exclusion (Luz and Portugal, 2021). When we assess the accessibility-activity participation relationship of a single individual, we can expect that some people may have a high level of accessibility but a poor level of activity participation. These individuals (a) do not prefer to participate frequently in activities, (b) there are other barriers to activity participation not included in the accessibility analysis (e.g., disabled people, mental barriers, social isolation) or (c) the accessibility analysis does not fit preference/needs of people well enough (e.g., maybe there is a school available but not of the right type). However, if we aggregate the individuals' data and test this relationship for a whole population at once, in that case, it is expected that higher levels of accessibility are associated with greater participation in activities, on average, and, consequently, a lower level of social exclusion (Luz and Portugal, 2021). In this sense, a helpful accessibility metric for assessing TRSE must be associated, at least in part, with the activity participation level. Otherwise, it is possible that the chosen accessibility measure does not represent the possibilities for individuals to participate in activities.

To the best of the authors' knowledge, only three previous studies that tested the relationship between accessibility and participation in activities were from the perspective of social inclusion or equity (Allen and Farber, 2020; Fransen et al., 2018; Cheng et al., 2019). Most studies investigated accessibility and participation in activities relationship from a trip generation perspective and, consequently, adopted an aggregated approach, failing to control people's interpersonal heterogeneity adequately. Moreover, most studies focus on Global North contexts, and empirical evidence for Global South contexts is scarce. Finally, and perhaps most importantly, none of the reviewed studies on the accessibility-activity participation relationship controlled for endogeneity (when one of the independent variables correlates with the regression error term) adequately. In the presence of endogenous variables, the consistency of the estimators is compromised, which may bias the results and hinder the identification of a cause-effect relationship between the explanatory and dependent variables. Past studies only attested to the association between variables but failed to identify the cause-effect relationship. The causal theory is vital for the practice of policy research. It is used to diagnose problems, predict future impacts of policy interventions, and assess the effectiveness of past interventions (Steinberg, 2007). However, policy design often fails to focus on causality, which is the true driving force of policy effect and therefore misconstrues the potential effectiveness of policy design (Capano and Howlett, 2021). Causality is the basis of explanation (why this happened?) and prediction (what might happen in the future?). The better we understand the causality of a system, the better our strategy for manipulating that system will be. 
Luz, G., Barboza, M. H. C., Portugal, L., Giannotti, M., van Wee, B. (2022). Does better accessibility help to reduce social exclusion? Evidence from the city of São Paulo, Brazil. Transportation Research Part A: Policy and Practice, 166, 186-217. https://doi.org/10.1016/i.tra.2022.10.005

Given the imperative of accessibility planning for inclusive transport policies, this article has three objectives: (a) to provide a conceptual model of the causal relationship between accessibility, activity participation and risk of transport-related social exclusion (TRSE), (b) to summarise the available empirical evidence about the accessibility-activity participation relationship through a systematic literature review, and (c) to provide evidence of the causal relationship between accessibility and activity participation in a context of the Global South to support transport policies. We assess the cause-effect relationship of accessibility-activity according to the type of activities accessed, mandatory activities (work and education), discretionary activities (leisure, shopping or having a meal), and total activities (without purpose distinction) in the city of São Paulo, Brazil. We developed three Poisson regression models associated with an instrumental variable identification strategy to control endogeneity in the relationship under study.

Unlike more recent studies on the topic that tend to use more sophisticated measures of accessibility, we decided to use the cumulative measure of accessibility opportunities (CUM) due to its simplicity, low data requirements, ease of interpretation and popularity among policymakers. Aspects such as ease of operationalisation and interpretation are crucial for the accessibility measure to be used by planners, especially in a Global South context, where transport agencies face data limitations and have poorly qualified technical staff (Barboza et al., 2021). Disaggregation is another feature that distinguishes our research from previous studies that employed place-based accessibility measures. We assessed the accessibility-activity participation relationship while considering the individual's accessibility level and his/her sociodemographic characteristics.

Sections 2.1 and 2.2. address the objectives (a) and (b), respectively. Section 3 describes the study area and regional context of the empirical part. Section 4 introduces the methodology and describes the instrumental variable identification strategy adopted to infer causality between accessibility and participation. Section 5 is dedicated to the descriptive statistics of our data. Section 6 presents the results and section 7 conclusions.

\section{Background}

\subsection{Transport-Related Social Exclusion (TRSE) and Accessibility}

An individual is socially excluded if "he or she is geographically resident in a society, but for reasons beyond his or her control, he or she cannot participate in the normal activities of citizens 
Luz, G., Barboza, M. H. C., Portugal, L., Giannotti, M., van Wee, B. (2022). Does better accessibility help to reduce social exclusion? Evidence from the city of São Paulo, Brazil. Transportation Research Part A: Policy and Practice, 166, 186-217. https://doi.org/10.1016/i.tra.2022.10.005

in that society, and he or she would like to so participate" (Burchardt et al., 1999, p. 229). According to Preston and Rajé (2007), a helpful way of thinking about social exclusion is to reshape Amartya Sen's theory of entitlement. Sen suggests that famines are not caused by a lack of food but by a lack of access to food (Sen, 1983). Similarly, social exclusion is not due to a lack of social opportunities but a lack of access to those opportunities (Preston and Rajé, 2007). In this sense, the transport system is critical in providing people access to activities, services, and opportunities dispersed in space (Farrington, 2007).

Given that the primary purpose of transport systems is to provide access to opportunities that people have reason to value (van Wee and Geurs, 2011; Martens, 2016a; Allen and Farber, 2020; Martens, 2016b), individuals can be deprived of participation in society and be at risk of transport-related social exclusion (TRSE) if these systems fail to achieve their purpose. Formally, transport-related social exclusion is defined as the process by which people are prevented from participating in the economic, political, and social life of the community because of reduced accessibility to opportunities, services, and social networks, due to in whole or in part, to poor potential mobility (Kenyon et al., 2002). It means that the partial or complete people's inability to traverse space limits individuals from reaching different opportunities, indicating accessibility poverty (Jeekel and Martens, 2017) which, in turn, can manifest itself in social exclusion (Luz and Portugal, 2021). Simply put, people at risk of TRSE are those in accessibility poverty. In this sense, transport policies aimed to promote social inclusion should increase the accessibility levels of those in accessibility poverty conditions (Luz and Portugal, 2021).

The accessibility notion was first introduced by Hansen (1959) in the late 50s and defined as the "potential of opportunities for interaction." However, its link with social exclusion emerged with UK policymakers in the early 2000s with the publication of the iconic report "Making the Connections: Transport and Social Exclusion", launched by the Social Exclusion Unit (2003). The Social Exclusion Unit (2003) document brought a new narrative to the accessibility notion: the ability of people to reach and take part in opportunities and activities normal for that society (Farrington and Farrington, 2005; Farrington, 2007; Social Exclusion Unit, 2003). From this point of view, accessibility is understood as an attribute of individuals in their interaction with the environment, considering how personal characteristics interact with the transport system, landuse, and political, economic, and social environment to shape the individuals' accessible opportunities set (Pereira et al., 2017; Lucas, 2006, 2012; Luz and Portugal, 2021).

Recently, many transport equity and TRSE studies advocate for the application of the Capabilities Approach to express concepts such as the accessibility narrative brought by TRSE literature 
Luz, G., Barboza, M. H. C., Portugal, L., Giannotti, M., van Wee, B. (2022). Does better accessibility help to reduce social exclusion? Evidence from the city of São Paulo, Brazil. Transportation Research Part A: Policy and Practice, 166, 186-217. https://doi.org/10.1016/i.tra.2022.10.005

(Bantis and Haworth, 2020; Hananel and Berechman, 2016; Martens, 2016a; Pereira et al., 2017; Luz and Portugal, 2021). According to those studies, the notion of accessibility as a human capability allows expressing the broad diversity of individuals and how they interact with transport and land use resources and the environment to determine people's participation opportunities (Vecchio and Martens, 2021; Luz and Portugal, 2021; Pereira et al., 2017). Although beneficial to articulate the TRSE accessibility narrative theoretically, the idea of accessibility as a human capability faces a practical challenge (Pereira et al., 2017). Accessibility as a human capability requires one to address accessibility as a result of a combination of personal abilities and perceptions, transport and land-use resources, and the political, social and economic environment, which is a much more complex and multidimensional concept than those used in conventional transport and accessibility studies (Pereira et al., 2017; Vecchio and Martens, 2021; Luz and Portugal, 2021).

Despite the wide range of accessibility measures developed over time (Geurs and van Wee, 2004; Handy and Niemeier, 1997; Kwan, 1998; Neutens et al., 2010), none of them alone can capture all the accessibility as human capability nuances (Luz and Portugal, 2021). Depending on the accessibility measure selected, some accessibility factors will be privileged while others will be neglected (Geurs and van Wee, 2004; Kamruzzaman et al., 2016; Martens, 2016a; Pyrialakou et al., 2016; Neutens et al., 2010; Kwan, 1998; Handy and Niemeier, 1997). Different accessibility measures account for different facets of how individuals interact with the spatial structure and distribution of opportunities (Fransen et al., 2018). In this sense, different accessibility measures might provide different insights into the equitable distribution of opportunities (Neutens et al., 2010) and, therefore, indicate different policy alternatives.

Figure 1 provides a conceptual model of the causal relationship between accessibility, activity participation, and transport-related social exclusion risk. Accessibility comprises four components: transport, land use, temporal and individual (Geurs and van Wee, 2004; Luz and Portugal, 2021; Lucas, 2012). The individual's accessibility, i.e. her capabilities, is defined by the transport and land use resources and their respective temporal constraints, plus the individual's perceptions and abilities to convert these resources into access options (Luz and Portugal, 2021; Pereira et al., 2017; Vecchio and Martens, 2021). The individual's ability to travel and access activities will be an outcome of the interaction between her capabilities, her political, economic, and social environment context and their needs and activity alternatives. The travel and activity participation needs will also be influenced by the individual's virtual accessibility (Hong and Thakuriah, 2016; Lavieri et al., 2018). There are four potential effects of virtual accessibility on trip making - substitution (save trips), complementarity (generate trips), modification (change 
Luz, G., Barboza, M. H. C., Portugal, L., Giannotti, M., van Wee, B. (2022). Does better accessibility help to reduce social exclusion? Evidence from the city of São Paulo, Brazil. Transportation Research Part A: Policy and Practice, 166, 186-217. https://doi.org/10.1016/i.tra.2022.10.005

planned activities or trips) and neutrality (negligible effect) (Mokhtarian and Salomon, 1997; Hong and Thakuriah, 2016).

The interaction of all these elements will influence trip making. Since trip making is rarely an end in itself, but usually a means to another end (activity participation), the higher the number of trips, the higher the number of activities an individual participates in. When accessibility conditions are insufficient to enable individuals to make the trip and access the desired activity, they become at risk of transport-related social exclusion.

Participation in activities and non-participation will impact the individual and temporal component of accessibility, creating a feedback loop (Luz and Portugal, 2021). Firstly, the temporal component accessibility will be affected by the restriction in an individual's time window to participate in activities. For example, given that the time budget a person has available to participate in activities is limited ( 24 hours minus the time she is sleeping and personal care, such as eating), the more (and longer) activities they engage in, the less time they have available to participate in other activities. For instance, longer mandatory activities, like work and education, combined with long trips to access it will leave less (or almost none) time budget for other activities. In other words, as they participate in more activities, their accessibility level reduces. Secondly, participation in activities may improve the individual's abilities and skills, expanding the range of activities (accessibility) in which she can participate in. In contrast, an individual who cannot access some types of activities may not be able to develop her skills and thus, will face limited accessibility to jobs. For example, people who participate in education-type activities can build skills and qualify for better jobs that were previously not accessible due to their previous qualifications. Or an older person who can practice physical exercise near their home can improve their physical mobility conditions, allowing them to get on the bus that was previously not accessible due to vehicle design or sudden stops. In sum, participation in activities may improve individuals' skills or physical condition, which, in turn, will expand the range of activities in which they can participate, even though there are limits in this process, as pointed by Figure 1 . 
Luz, G., Barboza, M. H. C., Portugal, L., Giannotti, M., van Wee, B. (2022). Does better accessibility help to reduce social exclusion? Evidence from the city of São Paulo, Brazil. Transportation Research Part A: Policy and Practice, 166, 186-217. https://doi.org/10.1016/i.tra.2022.10.005

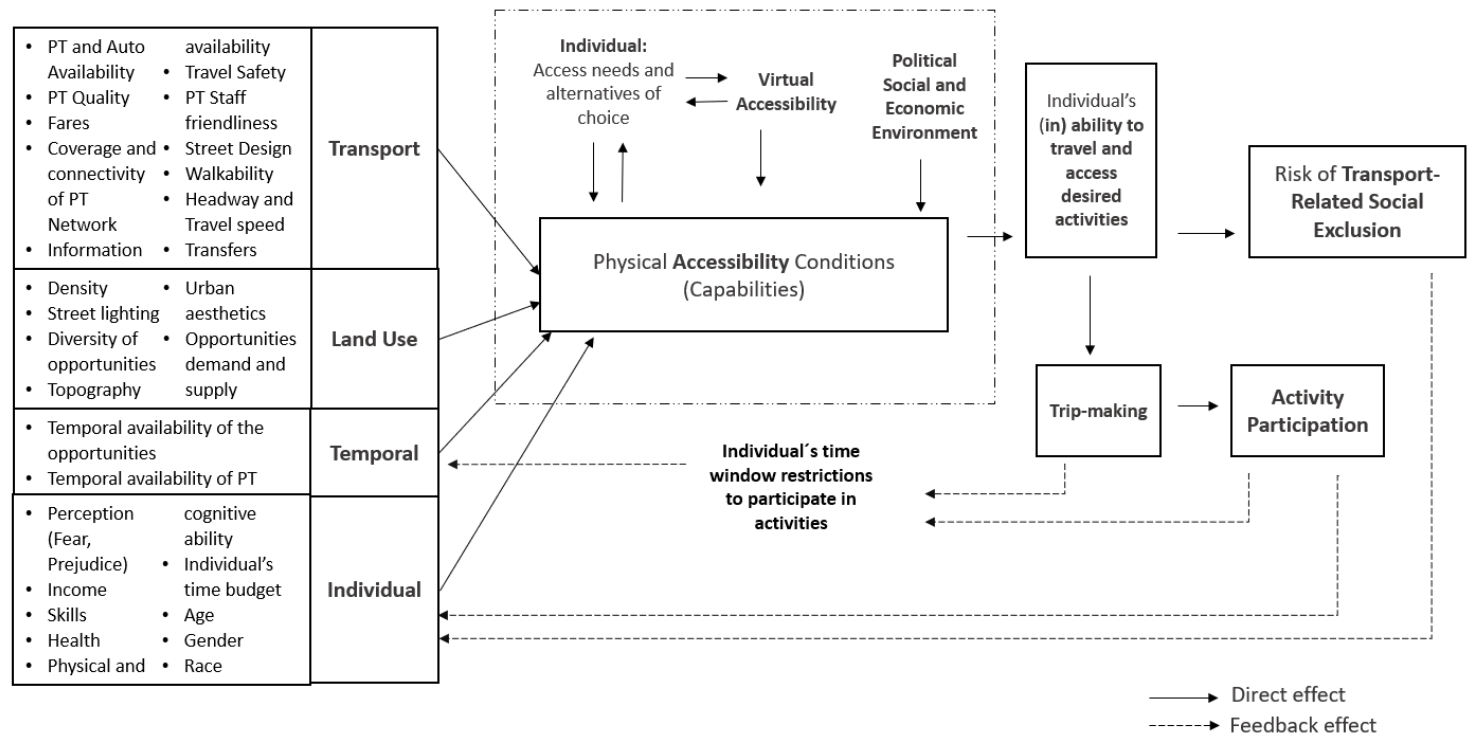

Figure 1: Conceptual model of the causal relationship between accessibility, activity participation, and the risk of transport-related social exclusion

Source: Authors' elaboration

Some sources of endogeneity in the presented framework may compromise the identification of a causal relationship between accessibility and activity participation. Wooldridge (2015) lists three traditional sources of endogeneity in applied econometrics: omitted variables, measurement errors and simultaneity. All three sources are present in the framework. First, the accessibility measures used in practice account only for some of the components that shape an individual's possibilities of participation. It means that they are subject to omitted variables since they do not capture all the accessibility factors and complex social interactions, perceptions, and behaviours that influence activity participation (Bantis and Haworth, 2020; Luz and Portugal, 2021; Curl et al., 2011). Even when many control variables are used to mitigate this source of endogeneity, some aspects such as perception, health, and physical and cognitive ability are challenging to measure. Second, measurement errors in accessibility variables and other independent variables are frequent in studies about the relationship between accessibility and activity participation. For example, when location-based accessibility measures are used, measurement errors regarding the actual position of the individual exist. Also, studies that calculate the accessibility based on GTFS data are subject to measurement errors since most GTFS data are based on a planned public transport timetable, which does not necessarily correspond to what happens in the real world. Other sources of measurement errors are related 
Luz, G., Barboza, M. H. C., Portugal, L., Giannotti, M., van Wee, B. (2022). Does better accessibility help to reduce social exclusion? Evidence from the city of São Paulo, Brazil. Transportation Research Part A: Policy and Practice, 166, 186-217. https://doi.org/10.1016/i.tra.2022.10.005

to the temporal availability of opportunities. Third, simultaneity is present in the feedback loops of the framework. Accessibility can affect the number of trips carried out and the number of activities the individual participates in. At the same time, trips made and activities in which she engaged affect her level of accessibility, as discussed previously.

Most transport equity and TRSE studies assume that increasing accessibility levels lead to increased activity participation and, therefore, a reduction of social exclusion. Although this assumption makes sense from a theoretical point of view, this causal relationship has not yet been validated in practice. In this regard, a more in-depth understanding of the relationship between the most conventional accessibility measures and activity participation is necessary to define sufficient levels of accessibility and design effective policies to mitigate TRSE (Martens, 2016b; Allen and Farber, 2020). However, there has been little empirical research about whether popular accessibility measures positively relate to activity participation and lower risk of social exclusion.

\subsection{Accessibility and Activity Participation}

Measuring accessibility in all its dimensions is highly complex; therefore, no accessibility measure adequately captures all possibilities for participation in activities (Martens, 2016a). Empirical evidence on whether accessibility levels correlate with activity participation; and whether a given accessibility measure reflects the individuals' participation possibilities are scarce in the literature. More evidence is found outside the TRSE literature on the relationship between accessibility and trip making. It is plausible that the number of trips made by an individual is directly related to the number of activities in which she/he participated (Allen and Farber, 2020; Merlin, 2015; Luz and Portugal, 2021). Hence, the evidence provided by this group of studies is also helpful in understanding if higher accessibility levels are related to more activity participation (Merlin, 2015) and thus reduced risk of TRSE.

We conducted a systematic literature review to collect empirical evidence about the relationship between accessibility and activity participation/trip-making. The materials reviewed in this section are primarily from articles published in journals. On 11 January 2022, a search was performed in the scientific base Scopus with the following combination of words: ( 1 "accessibility" ) AND ( "activity participation" OR "participation in activit*" OR "activity rates" OR "trip generation" OR "trip making" OR "trip rates" ) in the Title, Abstract or Keyword of the papers. The search returned 289 documents. After applying the filter for documents of the type "article", published in Journals and written in English, 211 papers remained in the sample. After 
Luz, G., Barboza, M. H. C., Portugal, L., Giannotti, M., van Wee, B. (2022). Does better accessibility help to reduce social exclusion? Evidence from the city of São Paulo, Brazil. Transportation Research Part A: Policy and Practice, 166, 186-217. https://doi.org/10.1016/i.tra.2022.10.005

reading the titles and abstracts of the 211 articles, 171 documents that did not investigate the relationship between accessibility and activity participation or trip-making were discarded, remaining only 40 documents. After carefully examining the 40 articles' full text, 23 out of 40 articles were included in the final literature selection. Finally, we used a forward and backward snowball technique to complement the literature review. The final literature reviewed thoroughly for this section consists of 38 articles. An overview and the key findings of the 38 articles review are presented in appendix A.

Evidence of the relationship under study is scarce for the Global South context, particularly in Latin American countries. Of the 38 articles reviewed, only five are in Global South countries (Ding et al., 2016; Cheng et al., 2019; Krasić and Novačko, 2015; Wang and Cao, 2017; Masoumi, 2021). Moreover, most studies (24) are related to travel forecasting and focus on understanding the relationship between accessibility and the number of trips made. Few studies (9) focus on assessing the relationship between accessibility and activity participation. Five articles have examined the relationship between accessibility, trip generation and activity participation. None of the reviewed studies that have focused on social exclusion and equity aspects related to accessibility provision (Fransen et al., 2018; Allen and Farber, 2020; Cheng et al., 2019) included causal inference methods as the present work does. Studies focusing on trip generation tend to adopt an aggregate approach, using zones as the unit of analysis. At the same time, most papers on activity participation utilise the individual or household as observation.

Most of the reviewed articles used place-based measures of accessibility. The most widely adopted accessibility measure was the gravity type (15 studies) and minimum or weighted distance or time to activities, transport stop or CBD (15 studies), followed by cumulativeopportunities measure (6 studies). Some authors adopted simpler place-based measures (container-type accessibility) that account for only the land use component of accessibility (households density, population density, jobs density, area characteristics) (5 studies) or only aspects of transport infrastructure ( 3 studies). Other accessibility measures found in the literature are utility-based measures and spatio-temporal measures, such as the volume and the number of activities within the space-time prism (Kitamura et al., 2001), available time for activity participation (Landau et al., 1981; Fransen et al., 2018) and Burns-Miller measure (Ding et al., 2016). Lavieri et al. (2018) further tested the influence of virtual accessibility on the level of participation in face-to-face activities.

Although we might expect higher accessibility levels to be associated with a greater number of trips and more activity participation from a theoretical point of view, the empirical results do 
Luz, G., Barboza, M. H. C., Portugal, L., Giannotti, M., van Wee, B. (2022). Does better accessibility help to reduce social exclusion? Evidence from the city of São Paulo, Brazil. Transportation Research Part A: Policy and Practice, 166, 186-217. https://doi.org/10.1016/i.tra.2022.10.005

not indicate a consensus regarding the validity of this statement. Thirteen articles found that accessibility levels are associated with higher trip making and activity participation (Allen and Farber, 2020; Calvo et al., 2019; Ding et al., 2016; Golob, 2000; Handy, 1996; Koenig, 1980; Krasić and Novačko, 2015; Leake and Huzayyin, 1980; Lee and Goulias, 1997; Merlin, 2015; Purvis et al., 1996; Robinson and Vickerman, 1976; Tian and Ewing, 2017), while seven studies found that this relationship is weak (Hanson and Schwab, 1987; Kitamura et al., 1997) or not statistically significant (Downes and Morrell, 1981; Ewing et al., 1996; Handy, 1993; Wang and Cao, 2017; Wermuth, 1982).

All the studies that adopted space-time accessibility measures identified a positive relationship with at least one type of activity participation. The studies that found no significant or weak effect were published before 1996 (except for Wang and Cao (2017)). Those papers used methods and data less sophisticated than the more recent papers. They all adopted place-based accessibility measures, and only one looked at the relationship between accessibility and activity participation (Wermuth, 1982). However, Wermuth(1982) applied a less robust accessibility measure, location characteristics, as a control variable in the ANOVA. The other five works were focused on trip-making.

Fourteen articles found mixed effects regarding the relationship between accessibility and activity participation/trip making. For example, Cordera et al. (2017) found that the validity of the relationship varies according to the mode of transport. While greater accessibility is associated with a decrease in the number of trips to work by private vehicles, they also found that it is related to an increase in public transport trips. Cheng et al. (2019) found that population density, considered by them to be a type of accessibility measure, significantly affects trip generation, but employment density does not. On the other hand, population and employment density variables show insignificant impacts on activity participation. Kröger et al. (2018) found that accessibility to the nearest business district positively impacts home-based shopping trips but not home-based work trips. Schwanen et al. (2007) suggest that men may take care of more household tasks in a neighbourhood with good accessibility to shops due to fewer space-time constraints. However, they also found that as the travel time to the nearest shopping centre for clothing or footwear rises, individuals participate more frequently in shopping for convenience goods independent of their spouse.

Kitamura et al. (2001) notice that the size of the space-time prism is the critical determinant of activity participation but not the number of opportunities within the prism. Fransen et al. (2018) findings indicate a moderate positive correlation between the available time for activity 
Luz, G., Barboza, M. H. C., Portugal, L., Giannotti, M., van Wee, B. (2022). Does better accessibility help to reduce social exclusion? Evidence from the city of São Paulo, Brazil. Transportation Research Part A: Policy and Practice, 166, 186-217. https://doi.org/10.1016/i.tra.2022.10.005

participation and partaking in discretionary activities. Despite the positive findings for the spacetime measure, Fransen et al. (2018)'s findings indicate that the gravity-type measure shows a negative and highly significant relationship to activity participation. Seo et al. (2013) found that maintenance trips are negatively associated with accessibility levels, while other purpose trips are positively associated. Thill and Kim (2005) tested 72 variations of accessibility measures. They found that half of the statistically significant accessibility variables revealed a positive relationship with trip making, while the other half indicated a negative relationship. According to Zhang et al. (2019)'s findings, people who live in denser neighbourhoods (considered by the authors an accessibility measure) are more likely to make more home-based work and shopping trips; however, household density negatively impacts participation in entertainment and social activities. Landau et al. (1981) found that time constraints were significant in the leisure trip models and not in the maintenance trip models. The number of employees in commerce and services in residential areas positively influences the number of maintenance trips but negatively influences leisure trip making. Finally, three studies found a strictly negative relationship between accessibility and activity participation or trip making (Lavieri et al., 2018; Williams, 1989; Wu et al., 2012). Williams (1989) found that activity participation reduces as accessibility increases and that there is no association between the number of trips made and the accessibility conditions. Although Wu et al. (2012) and Lavieri et al. (2018) found a negative relationship, their findings are reasonable according to the theoretical literature. $\mathrm{Wu}$ et al. (2012) findings indicate that higher walking and public transport accessibility levels are associated with fewer trips by car. Lavieri et al. (2018) findings indicate that virtual accessibility negatively impacts the number of physical maintenance activities. However, Lavieri et al. (2018) also found that physical accessibility negatively impacts the number of maintenance activities and that individuals who perceive ease of access to opportunities tend to concentrate their maintenance activities in fewer and longer episodes.

Some conclusions can be drawn from the empirical evidence within this literature review on the relationship between accessibility and activity participation or trip making. First, there is no consensus on whether greater levels of accessibility lead to greater activity participation or trip making. Secondly, very few studies have investigated this relationship from TRSE and transport equity perspectives, and most looked at this relationship from a trip generation perspective. Thirdly, due to their focus, those studies applied accessibility measures aggregated by zones and failed to adequately control people's interpersonal heterogeneity. However, the TRSE literature points out that individual characteristics play an essential role in an individual's chances of participation in society (Luz and Portugal, 2021). Fourth, most studies focus on Global North 
Luz, G., Barboza, M. H. C., Portugal, L., Giannotti, M., van Wee, B. (2022). Does better accessibility help to reduce social exclusion? Evidence from the city of São Paulo, Brazil. Transportation Research Part A: Policy and Practice, 166, 186-217. https://doi.org/10.1016/i.tra.2022.10.005

contexts, and empirical evidence is scarce for Global South contexts. Fifth, given the variability of the findings, one of the hypotheses to be raised is that this relationship is sensitive to the quality of the data and the sophistication of the methods used. Also, likely, this relationship is context-specific.

All studies reviewed in this section investigated only the correlational relationship between accessibility measures and activity participation. Although studies that don't operationalize accessibility measures are out of the scope of the present literature review, it's worth mentioning two studies ${ }^{1}$ (Miller et al., 2015; Zhang et al., 2021) that assess the causal relationship through before/after studies, and account for variables related to accessibility in a broader aspect. Those studies used a before/after quasi-experimental design. Using GPS systems and accelerometers, Miller et al. (2015) assessed changes in the physical activity pattern of study participants before and after the Light Rail Transit construction and evaluated differences in these patterns while controlling for sociodemographic variables in Salt Lake City, Utah, United States. Miller et al. (2015) point out that public transit in the neighbourhood contributes to individuals undertaking new physical activities. Although the study does not directly apply an accessibility measure, the construction of the LRT has increased accessibility in the region. Zhang et al. (2021) investigated how the launch of on-demand transit services changed patterns of nightlife activity participation of socially disadvantaged individuals in Belleville, Ontario, Canada. Zhang et al. (2021) found that users' satisfaction with reliability and service quality is positively associated with activity participation. Despite Zhang et al. (2021) not using a conventional accessibility measure, the reliability and service quality improvement may be seen as an increase in accessibility.

Unlike the present work, none of the reviewed studies used identification strategies to infer a causal relationship between accessibility measures and activity participation or trip making. One may argue that structural equation modelling (SEM) can account for the causal relationships between the variables included in the model. However, Bollen and Pearl $(2013$, p. 308) argue that "developers and users of SEMs are under the mistaken impression that SEMs can convert associations and partial associations among observed and/or latent variables into causal relations." For a more in-depth discussion, see Bollen and Pearl (2013).

Much of the TRSE research treat accessibility as a critical indicator of the number of opportunities available to individuals. From a theoretical perspective, such a statement makes

\footnotetext{
${ }^{1}$ The two papers (Miller et al., 2015; Zhang et al., 2021) were added based on a suggestion of a reviewer.
} 
Luz, G., Barboza, M. H. C., Portugal, L., Giannotti, M., van Wee, B. (2022). Does better accessibility help to reduce social exclusion? Evidence from the city of São Paulo, Brazil. Transportation Research Part A: Policy and Practice, 166, 186-217. https://doi.org/10.1016/i.tra.2022.10.005

complete sense. However, previous studies investigating the accessibility-participation relationship were inconclusive, indicating that increasing accessibility has a limited impact on activity participation levels, if any (Fransen et al., 2018; Martens, 2016a). It may suggest that the link between accessibility and activity participation is less direct than expected. In this sense, evaluating policy interventions using accessibility measures may lead to misleading results regarding the possible impacts on activity participation (Martens, 2016) and, therefore, on social exclusion.

\section{Study Area and regional context}

The study focuses on the City of São Paulo, Brazil, Latin America's largest city and home to more than 12 million people. São Paulo's development illustrated Brazil's fast urbanisation process throughout the last century when the city had average annual growth rates of more than 4.5 per cent until 1950 (Moreno-Monroy and Ramos, 2020). Following the 1950s, the city had its most significant development driven by the placement of industrial parks, leading to an ongoing spatial reconfiguration closely linked to a traditional monocentric pattern (Moreno-Monroy and Ramos, 2020). In the following decades, the unmanaged centrifugal expansion developed a wide suburban outer belt filled by the poor and less educated population (Moreno-Monroy and Ramos, 2020). Consequently, the locations with lower levels of job accessibility are also those with poorer socioeconomic status, shorter life expectancies and disproportionally precarious infrastructure (Slovic et al., 2019).

Due to uncontrolled urban expansion, the historical prioritisation of private over collective modes of transport, and a suboptimal and uneven provision of urban public transport, a considerable share of the more disadvantaged population faces low accessibility levels and, therefore, longer commuting times and distances (Slovic et al., 2019; Boisjoly et al., 2020; Biderman, 2008). The weaker transport connectivity in regions farther from the wealthier central areas and the concentration of jobs in the CBD prevent carless workers from accessing potential employers far from the focal points of public transport accessibility (Haddad and Barufi, 2017; Boisjoly et al., 2017). As a result, access to opportunities is constrained for this population group, making São Paulo much more unequal than Global North cities (Giannotti et al., 2021).

The 2017 São Paulo Origin-Destination (OD) Survey estimates that 42 million trips are made daily in the Metropolitan Region of São Paulo, 67\% in motorised vehicles and 33\% in non-motorised modes (Companhia Metropolitana do Metrô, 2017). Among the motorised trips, approximately $54 \%$ occur in collective modes, while $46 \%$ are in private vehicles. There is a high public transport 
Luz, G., Barboza, M. H. C., Portugal, L., Giannotti, M., van Wee, B. (2022). Does better accessibility help to reduce social exclusion? Evidence from the city of São Paulo, Brazil. Transportation Research Part A: Policy and Practice, 166, 186-217. https://doi.org/10.1016/i.tra.2022.10.005

dependency among low-income households. When evaluated by income bracket, $72 \%$ of families' trips with monthly incomes up to $U \$ 580^{2}$ occur by public transport, while in the highest income group U\$3484, only $20 \%$ are made by public transport (Companhia Metropolitana do Metrô, 2017).

\section{Methodology}

This paper focuses explicitly on inferring a causal relationship between accessibility levels and activity participation in a Global South context, the city of São Paulo. The study focuses on the social consequences of activity participation rather than the implications of particular travel demand. In this sense, we do not differentiate the activities individuals access by transport mode. We assessed the accessibility-activity participation relationship according to the type of activities accessed, mandatory activities (work and education), discretionary activities (leisure, shopping or having a meal), and total activities (without distinguishing between purposes).

The methodology section is organised into four parts. The next subsection describes the database used in the study. Subsection 4.2 presents the accessibility indicator adopted in the analysis. Subsection 4.3 describes the econometric models and the rationale for their choice. Finally, subsection 4.4 discusses the identification strategy adopted to control the models' endogeneity and allow inference of causality between accessibility and activity participation.

\subsection{Data}

The data used in this research come from different databases, such as the 2017 Origin and Destination (OD) Survey of the São Paulo Metropolitan Region (Companhia do Metropolitano de São Paulo - Metrô, 2019); Access to Opportunities Project (AOP) (Pereira et al., 2019); 2010 Demographic Census of the Brazilian Institute of Statistical Geography (Instituto Brasileirode Geografia e Estatística - IBGE, 2011); and the 2010 Paulista Social Vulnerability Index (Fundação Sistema Estadual de Análise de Dados, 2013).

Data on individuals' activities were taken from the 2017 RMSP Origin and Destination (OD) Survey. The OD survey collects information regarding daily trips within the Metropolitan Region of São Paulo and sociodemographic data from households, families, and individuals. The OD Survey data is collected from households chosen through sampling. All individuals answer a questionnaire about their sociodemographic information and trips made on the weekday before

\footnotetext{
21 US Dollar (U\$) = 3,29 Brazilian Real (R\$). April 2018 values.
} 
Luz, G., Barboza, M. H. C., Portugal, L., Giannotti, M., van Wee, B. (2022). Does better accessibility help to reduce social exclusion? Evidence from the city of São Paulo, Brazil. Transportation Research Part A: Policy and Practice, 166, 186-217. https://doi.org/10.1016/i.tra.2022.10.005

the OD Survey taker's visit. The data of the 2017 OD Survey were collected between June 2017 and October 2018, except for the school holiday periods, which were considered atypical for conducting the survey.

Data at the individual level were extracted from the OD 2017 Survey database exclusively for the São Paulo municipality. The choice to conduct the research only within the city of São Paulo is justified by the unavailability of accessibility data for the entire metropolitan region. The selected variables include age, gender, study status, level of education, employment status, number of family members, individual monthly income, and family status. Individuals aged 13 or younger were removed from the data set because they depend on other family members to travel and participate in activities. New variables were generated from the original database by dividing the number of private vehicles (cars and motorcycles) and family monthly income by the number of people in the family.

Variables regarding the number of activities the individual participated in were created from the travel diary. Trips to destinations other than home were considered an activity in the "total activities" category, trips for work or study purposes to destinations other than home were considered a mandatory activity, and trips for discretionary purposes (leisure, shopping or having a meal) to destinations other than home were counted as a discretionary activity. It is important to note that the sum of discretionary activities and mandatory activities does not equal the number of total activities. Some categories, such as travel for health purposes, were only included in the total activities category.

Since the OD Survey does not account for individuals' race, we tried to incorporate this aspect by calculating the proportion of declared black people living in the hexagon where the individual lives. Although this data was taken from the AOP, it originally came from the 2010 IBGE Demographic Census.

The third database used was the 2010 Paulista Index of Social Vulnerability (IPVS), produced by the State of São Paulo Legislative Assembly. The IPVS is calculated based on information from the 2010 IBGE Demographic Census and considers information on income, health, participation in the labour market, access to public services and opportunities for social mobility. The IPVS is divided into six levels that vary according to the combination of these variables; however, for this study, we grouped these six levels into two categories: living in a region of high social vulnerability and not living in a region of high social vulnerability. The use of all categories would imply too few observations in some categories, and the differentiation between the levels is quite subtle and not relevant to the scope of this study. 
Luz, G., Barboza, M. H. C., Portugal, L., Giannotti, M., van Wee, B. (2022). Does better accessibility help to reduce social exclusion? Evidence from the city of São Paulo, Brazil. Transportation Research Part A: Policy and Practice, 166, 186-217. https://doi.org/10.1016/i.tra.2022.10.005

Most of the sociodemographic and built environment variables selected were adopted in previous studies that assessed the accessibility-activity participation relationship from an equity perspective, such as age, gender, per capita income and vehicle ownership, study status, family status, level of education and population density (Fransen et al., 2018; Allen and Farber, 2020; Cheng et al., 2019).

After merging the different databases to the OD Survey data and generating the new variables based on this data, we excluded observations that were not complete, resulting in a sample of 47,167 individuals. Those individuals where the value of their accessibility was not available in the Access to Opportunities Project (AOP) database were excluded from the sample. Approximately $1.83 \%$ of the sample was removed (877 observations).

\subsection{Accessibility Measure}

The accessibility data used in this study was extracted from the Access to Opportunities Project (AOP) of the Institute for Applied Economic Research (IPEA) (Pereira et al., 2019). AOP aims to understand transport conditions and inequalities of access to opportunities in Brazilian cities. The AOP estimates the population's access to job opportunities by public transport in the largest urban regions in Brazil annually. Such estimates are made using GTFS (General Transit Feed Specification) data on public transport provided by the municipalities, data on the road network for September 2019 from the Open Street Map website, data from the 2010 Demographic Census of the Brazilian Institute of Statistical Geography (IBGE) and data on formal employment from the 2017 Annual Social Information Report (RAIS) of the Ministry of Labour.

Job accessibility variables by public transport were selected from the AOP database. Accessibility levels were measured using the cumulative opportunity measure (CUM) and depict the proportion of formal jobs in the municipality accessed by public transport within a given travel time threshold. Computed travel times were calculated during peak hours and included walking to and from stops, waiting for a transit vehicle, time spent travelling in a transit vehicle, and any time spent transferring between vehicles. The accessibility values calculated by the AOP have a high spatial resolution, with values aggregated in $\mathrm{H} 3$ hexagons at resolution 9, developed by technology company Uber. More specifically, the values are aggregated in hexagons of 174.38 meters side. The level of accessibility of the OD Survey respondent was determined by the latitude and longitude of her household. That is, the individual's accessibility level was assigned according to the hexagon in which her home was located.

The CUM measure is defined as follows: 
Luz, G., Barboza, M. H. C., Portugal, L., Giannotti, M., van Wee, B. (2022). Does better accessibility help to reduce social exclusion? Evidence from the city of São Paulo, Brazil. Transportation Research Part A: Policy and Practice, 166, 186-217. https://doi.org/10.1016/i.tra.2022.10.005

$$
C U M=\frac{\sum_{j} \quad a_{j} h_{\delta}\left(c_{i j}\right)}{N}
$$

Where $a_{j}$ is the number of jobs in $j, \delta$ is the time threshold, $c_{i} j$ the travel time between an individual's location $(i)$ and location $j$, and $h_{\delta}\left(c_{i} j\right)$ assumes the value one if $c_{i} j \leq \delta$ and 0 if $c_{i} j>\delta$, and $\mathrm{N}$ is the total number of formal jobs in the São Paulo municipality. Four different travel times by public transport thresholds were tested: 30, 60, 90 and 120 minutes. Despite the limitation of our accessibility data that is restricted to employment opportunities, Allen and Farber (2020) and Cordera et al. (2017) pointed out that employment distributions are theorised to be a proxy for many other types of potential destinations (e.g., services, stores, informal jobs, etc.). Thus, the accessibility values used are reasonable estimates of the level of accessibility to general activities in the city.

The CUM measure was selected due to the unanimity among researchers concerning its ease of operationalisation, communication, and interpretation (Koenig, 1980; Geurs and van Wee, 2004; Neutens et al., 2010; Curl et al., 2011; Neutens, 2015). It is one of the most used accessibility measures in practice (Boisjoly and El-Geneidy, 2017b). CUM requires only information regarding opportunities' quantity and spatial distribution, and travel time from the reference location to these opportunities. It does not require data regarding the attractiveness of the activities and does not require the adoption of a transport deterrence function with a calibrated parameter. In addition, the computational power demanded to calculate CUM is considerably lower than other more realistic measures, allowing the application at the macro scale, such as entire cities and metropolitan regions. Due to the less powerful equipment requirements, CUM is much easier to implement by technicians in transportation planning agencies and interpreted by policymakers and the population, which is crucial in the Global South context, where most transport agencies face data limitations and have low-skilled technical staff (Barboza et al., 2021).

From the perspective of accessibility as a human capability, one should ideally adopt a personbased accessibility measure that accounts for as many as possible personal characteristics that shape an individual's accessibility. However, many policy evaluations and interventions use cumulative opportunities measure as a metric to assess equity and risk of transport-related social exclusion. In this sense, we want to test whether one of the most straightforward and commonly used measures in practice still has a causal effect on activity participation. In other words, we want to check whether even a measure that captures only some characteristics of the transport and land-use components of accessibility is still a valuable tool to inform more inclusive transport policies. 
Luz, G., Barboza, M. H. C., Portugal, L., Giannotti, M., van Wee, B. (2022). Does better accessibility help to reduce social exclusion? Evidence from the city of São Paulo, Brazil. Transportation Research Part A: Policy and Practice, 166, 186-217. https://doi.org/10.1016/i.tra.2022.10.005

\subsection{Activity participation models}

The proposed models estimate whether accessibility influences the total, mandatory and discretionary activities carried out by individuals. More specifically, we intend to assess if higher accessibility levels cause more activity participation and, therefore, reduce the risk of TRSE. Our dependent variables are counts and follow a similar distribution to Poisson. The total activities variable has the mean precisely equal to the variance, while the variables of mandatory activities (work and study) and discretionary activities (leisure, shopping and having a meal) have variance values very close to the mean. In addition, we conducted tests for overdispersion (when the residual deviance is higher than the degrees of freedom of the model) proposed by Cameron and Trivedi (1990). According to the test, the total and mandatory activities variables did not present overdispersion. On the other hand, the discretionary activities variable presented statistical significance for dispersion. However, the dispersion value $(\eta)$ identified was tiny

(0.02). Griffith (2013) suggests that if $0 \leq \eta \leq \frac{0.5}{\lambda}$ Overdispersion will not pose a problem, and there will be little gain in replacing the Poisson regression model with a Negative Binomial model. For the discretionary activities model, we have $\left((\eta=0.02) \leq \frac{0.5}{0.18}=2.78\right.$, which indicates that overdispersion will not cause problems to the Poisson regression model. Furthermore, as Cameron and Trivedi (2009) pointed out, robust standard errors in the model can control for smooth violations in the equidispersion property. Table 9 presents the descriptive statistics of the dependent variables.

Table 9 -Descriptive statistics of dependent variables

\begin{tabular}{lllllllll}
\hline Dependent Variable & $\bar{x}$ & $\mathbf{S}$ & $\mathbf{s}^{\mathbf{2}}$ & Min & Max & Skewness & n & \% zeros \\
\hline Total Activities & 1.10 & 1.10 & 1.00 & 0 & 13 & 1.58 & 47167 & $28 \%$ \\
Mandatory / Fixed activities & 0.78 & 0.86 & 0.74 & 0 & 13 & 1.39 & 47167 & $43 \%$ \\
Discretionary / Flexible activities & 0.18 & 0.44 & 0.19 & 0 & 7 & 2.88 & 47167 & $84 \%$ \\
\hline
\end{tabular}

We tested four job accessibility variables, with 30, 60, 90 and 120 minutes of public transport travel time threshold. The 90 minutes threshold accessibility variable presented a higher residual deviation after its introduction in each model. It indicated that the best accessibility variable would be the one with 90 minutes threshold, as a higher residual deviation best explains dependent variables (Roback and Legler, 2021). Quadratic and cubic specifications for accessibility variables were tested to assess the best fit for the mathematical relationship 
Luz, G., Barboza, M. H. C., Portugal, L., Giannotti, M., van Wee, B. (2022). Does better accessibility help to reduce social exclusion? Evidence from the city of São Paulo, Brazil. Transportation Research Part A: Policy and Practice, 166, 186-217. https://doi.org/10.1016/i.tra.2022.10.005

between accessibility-activity participation. However, the best specification for all three models was linear.

We also tested a logistic transformation (Equation 2) of the accessibility measures used by Allen and Farber (2020) to obtain a sigmoid relationship between accessibility and activity participation. In this transformation, $\mathrm{A}$ is the accessibility value, $k$ is the curve's steepness, and $A_{m}$ is the value at the midpoint of the curve (i.e. the value of accessibility where the slope is at maximum). We use Akaike's information criterion (AIC) (Akaike, 1973) to compare the models. The improvement in the explanatory power of the model obtained with the sigmoidal transformation of the accessibility was negligible. Moreover, the value of the parameters associated with the best AIC were $k=2.8$ and $A_{m}=1.0$. However, with such specifications, the shape of the curve of the relationship between accessibility and participation in activities is practically identical to the shape obtained with the Poisson model without the accessibility logistic transformation (discussed in section 6.2). In this sense, to maintain the interpretability of the accessibility coefficients, we opted to maintain the Poisson model without the sigmoidal transformation of accessibility.

$$
f(A)=\frac{1}{1+e^{\left(-k\left(A-A_{m}\right)\right)}}
$$

Control variables related to the sociodemographic information of individuals and characteristics of the region where the individual lives were also added to the models. Such variables were selected based on the transport-related social exclusion literature and the previous works on the relationship between accessibility and activity participation/trip making revised in section 2.2 and include family monthly income per capita, age, private vehicles ownership, gender, number of people in the family, the proportion of black people in the region, study status, family status, employment status, social vulnerability region, level of education, individual income, populational density, family status and presence of dependent children and elderly in the household. We consider all people under 18 or above 65 years old living with others in the same residence as a proxy for a dependent.

The existence of multicollinearity was assessed using the variance inflation factor (VIF). None of the variables presented a VIF value greater than 5 , indicating no multicollinearity problems among the independent variables included in the models. Moreover, LOESS-type non-linear models were used to assess the relationship between independent variables and the number of activities carried out. Some variables, such as family monthly income per capita, age and number of residents in the household, presented a quadratic relationship with the log of the number of activities. Only the variables that showed a drop in the residual deviance (increased the model's 
Luz, G., Barboza, M. H. C., Portugal, L., Giannotti, M., van Wee, B. (2022). Does better accessibility help to reduce social exclusion? Evidence from the city of São Paulo, Brazil. Transportation Research Part A: Policy and Practice, 166, 186-217. https://doi.org/10.1016/i.tra.2022.10.005

explanatory power) were added to the model. The best models were selected using Akaike's information criterion (AIC).

Given the large proportion of zeros in the sample, it seems plausible to think that a zero-inflated model would better fit the explanatory variables. However, the large proportion of zeros does not necessarily mean an excess of zeros. Evaluating Poisson distributions with incidence rates $(\lambda)$ equal to the mean for the model's dependent variables (number of total activities, number of mandatory activities and number of discretionary activities), we found that the number of zeros in the sample is within the expected for such distributions. In this sense, there is no need to use a zero-inflated model.

Finally, the generic Poisson regression model for estimating the participation in total, mandatory and discretionary activities is defined as follows:

$$
\lambda_{i}=\exp \left(\beta_{0_{i}}+\beta_{1_{i}} X_{1}+\beta_{2_{i}} X_{2}+\beta_{3_{i}} X_{3}\right)
$$

where,

$\lambda_{i}$ - Number of activities in which the individual participated. ( $i=$ Total, mandatory, discretionary)

$\beta_{0_{i}}$ - Intercept.

$X_{1}$ - Accessibility by public transport variable calculated from the CUM measure with a 90minute threshold.

$X_{2}$ - Vector of variables with individual sociodemographic information.

$X_{3}$ - Vector of variables with information regarding the urban environment of the individual's residence

$\beta_{1_{i}}, \beta_{2_{i}}, \beta_{3_{i}}$ - Coefficients or coefficient vectors of the respective independent variables

It is important to note that the variable of total activities individuals participated in is not equal to the sum of mandatory and discretionary activities variables. The total activities variable includes activities such as visiting a doctor, job search, and others, which are not included in the mandatory and discretionary categories.

Since we are not necessarily interested in making the results representative of the whole population in the region but in assessing the causal relationship between accessibility levels and participation in activities, we opted not to use the expansion factors of the OD Survey. It would bring additional uncertainty to the model without contributing to our primary goal. 
Luz, G., Barboza, M. H. C., Portugal, L., Giannotti, M., van Wee, B. (2022). Does better accessibility help to reduce social exclusion? Evidence from the city of São Paulo, Brazil. Transportation Research Part A: Policy and Practice, 166, 186-217. https://doi.org/10.1016/i.tra.2022.10.005

We adopted an instrumental variable identification strategy to avoid endogeneity problems in the models and, consequently, to infer causality between the level of accessibility and the number of activities carried out. The following section describes the strategy and presents the reasoning for selecting the instrument. The models for the total, mandatory, and discretionary activities dependent variables before the application of the instrument are available in appendix B.

\subsection{Endogeneity and Instrumental Variable}

In a regression, the error or disturbance term represents factors other than $x$ that affect $y$. When one of the independent variables correlates with the regression error term $(u)$, this variable is endogenous (Wooldridge, 2015). In the presence of endogenous variables, the consistency of the estimators is compromised, preventing the identification of a cause-effect relationship between the explanatory and dependent variables. Hence, it is essential to use some identification strategy to control endogeneity and thus infer the causal effect of accessibility on activity participation. The best way to control endogeneity is to use natural experiments or policy-induced "quasi-random" changes in accessibility (Bastiaanssen et al., 2021). Since neither of these approaches is possible due to the cross-section nature of the database, we decided to apply an identification strategy based on an instrumental variable (IV).

Cunningham (2021) suggests drawing on a DAG (directed acyclic graph) 2 that shows a chain of causal effects to understand the IV technique. In our model, variable $Z$ denotes the instrumental variable, $D$ the accessibility variable, $Y$ the number of activities an individual has participated in, and $u$ are all the unobservable factors affecting accessibility and activity participation. A better understanding of the factors affecting accessibility and participation in activities and the direction of these effects can be obtained from Figure 1. To control the endogeneity of $D$ (accessibility) and be able to determine its causal effect on $Y$ (activity participation), one must choose an instrument that meets three criteria (Cunningham, 2021):

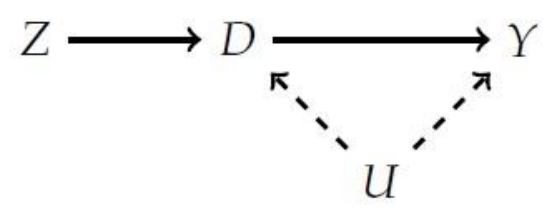

Figure 2: DAG (directed acyclic graph)

Source: Cunningham (2021) 
Luz, G., Barboza, M. H. C., Portugal, L., Giannotti, M., van Wee, B. (2022). Does better accessibility help to reduce social exclusion? Evidence from the city of São Paulo, Brazil. Transportation Research Part A: Policy and Practice, 166, 186-217. https://doi.org/10.1016/i.tra.2022.10.005

1. Z must be highly correlated and have a causal effect on $D$ or share a common cause;

2. $Z$ must affect $Y$ only through D. There is no direct effect of $Z$ on $Y$ (Exclusionary constraint).

3. $Z$ is not correlated with or is independent of $u$ and, therefore, does not share a common cause with outcome $Y$. The instrument $Z$ must not be correlated with the regression residuals of $D$ on $Y$.

The instrumental variable method allows estimating the average effect of $D$ on $Y$ through the instrument $Z$, irrespective of having measured the other (omitted) variables necessary to control for the effects $(u)$ that may cause confusion in the estimation of $Y$. The instrumental variable estimator bypasses the need to adjust for confounding variables by estimating the average effect of $D$ on $Y$ from two effects of $Z$ : the average effect of $Z$ on $D$ (first stage) and the average effect of $Z$ on $Y$ (second stage). These two estimated effects are consistent since $Z$ is randomly determined and does not correlate with the errors. As a result, it is possible to identify the causal effect of $D$ (accessibility measured by $C U M$ ) on the number of activities individuals participate in $(Y)$.

A good instrument for our model, therefore, must be highly correlated and have a causal effect or share a common cause with the accessibility variable (endogenous variable), must affect the number of activities in which individuals participate in only through accessibility, not share common causes with the activity participation and be randomly determined. Simply put, the instrument must be correlated with the number of activities in which individuals participate only through accessibility.

The selection of the instrumental variable was based on previous studies (Duranton and Turner, 2011; Jin and Paulsen, 2018; Haddad and Barufi, 2017), which suggest that geography is a strong determinant of transport infrastructure in a city. More specifically, the strategy adopted is the same that Haddad and Barufi (2017) used to assess the impact of accessibility on wages in the São Paulo metropolitan region. The proposed strategy is based on including a geographical/historical variable, the river shore distance to the first school built by the Jesuits in Sao Paulo, the city's founding location currently known as Pateo do Collegio.

The instrumental variable was calculated from a georeferenced watershed database where the municipality of São Paulo is located. The distance in kilometres from each location in the database to Pateo do Collegio by the nearest river shore was estimated using the Network Analysis tool of the QGIS software version 3.16.8. Figure 3 presents the water streams in the municipality of São Paulo, and Pateo do Collegio location.

Figure 3: Water Streams in the city of São Paulo 
Luz, G., Barboza, M. H. C., Portugal, L., Giannotti, M., van Wee, B. (2022). Does better accessibility help to reduce social exclusion? Evidence from the city of São Paulo, Brazil. Transportation Research Part A: Policy and Practice, 166, 186-217. https://doi.org/10.1016/i.tra.2022.10.005

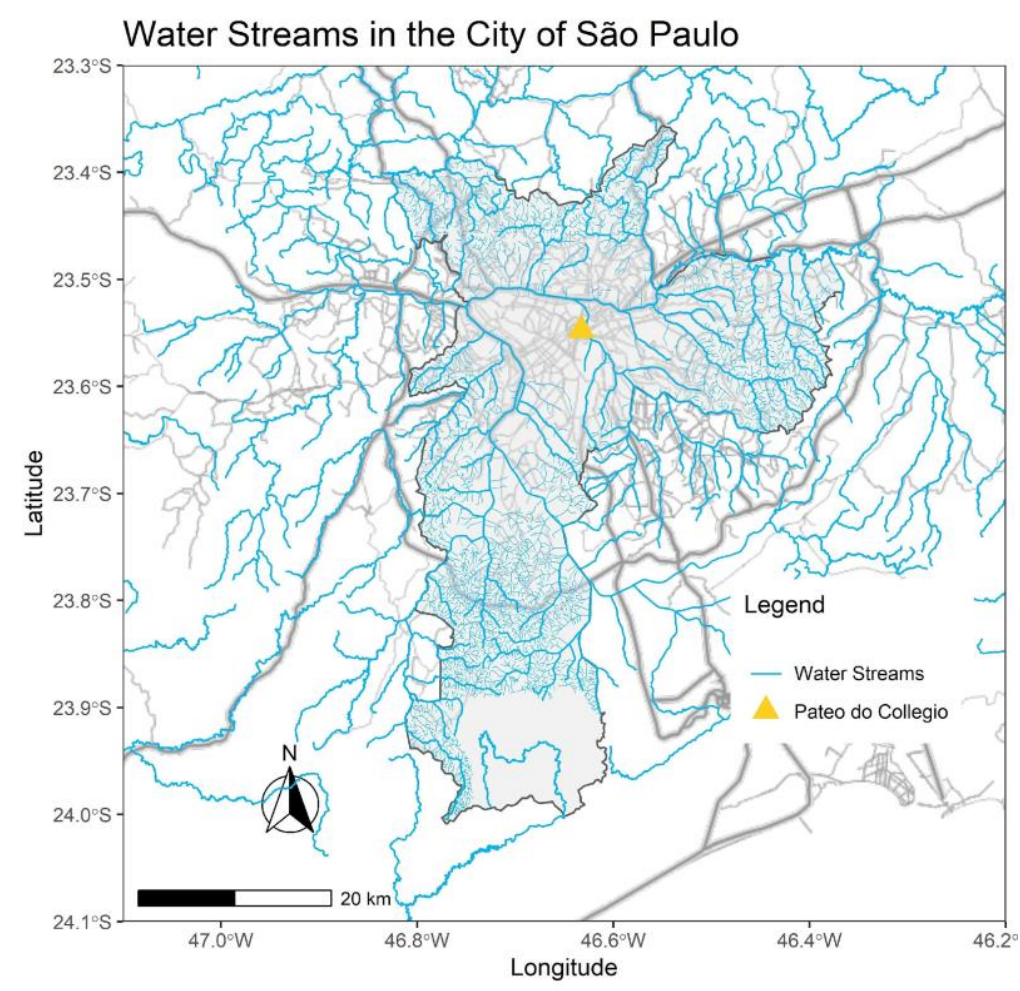

Source: Authors' elaboration

The reasoning for the choice of the instrument was the same adopted by Haddad and Barufi (2017). According to the authors, geography acted as a determinant of the location of transport infrastructure in the region. Consequently, the road network presents a strong spatial correlation with the existing water streams before urbanisation. It means that the instrument $Z$, the distance to Pateo do Collegio by the river shore, was naturally/randomly determined by the region's geography. Haddad and Barufi (2017) further provide a historical perspective on the instrument's validity. According to the authors, in the mid-nineteenth century, the city of São Paulo started a systematic occupation of the city's floodplains due to the implementation of regional and urban rail and road infrastructure. In 1929, the Plano de Avenidas further reinforced the occupation of river floodplains by focusing on developing wide avenues along the talweg. Still, according to Haddad and Barufi (2017), this conception of using the floodplains as a preferential space for circulation prevailed in the following plans of the city. Today, talweg avenues are the main arterial roads in the town of São Paulo (Meyer et al., 2004). Based on geographical and historical justifications, the exogeneity of the instrument seems plausible.

Pearson's correlation coefficient between accessibility by public transport measured using the CUM measure with a 90-minute threshold and the distance to Pateo do Collegio by the nearest river shore was statistically significant and strongly correlated $(-0.637)$. The correlation between 
Luz, G., Barboza, M. H. C., Portugal, L., Giannotti, M., van Wee, B. (2022). Does better accessibility help to reduce social exclusion? Evidence from the city of São Paulo, Brazil. Transportation Research Part A: Policy and Practice, 166, 186-217. https://doi.org/10.1016/i.tra.2022.10.005

the instrument and the three dependent variables (Total activities, Mandatory/Fixed activities and Discretionary/Flexible activities) and between the instrument and the estimated models' residuals presented an R-squared coefficient very close to zero (0.009 for total activities, 0.004 for mandatory activities and 0.006 for discretionary activities).

Since the model estimated in the previous section is not a linear regression model, the popular technique of applying the instrumental variable via two-stage least square (2SLS) estimation is not applicable (Cameron and Trivedi, 1998). Specifically, first-stage regression of an endogenous regressor on instruments followed by second-stage Poisson regression with the endogenous regressor replaced by its first-stage predicted value leads to inconsistent parameter estimates (Windmeijer and Silva, 1997). In this case, using the generalised method of moments (GMM) is recommended to estimate the Poisson regression model with endogenous regressors. Considering that the Poisson regression model does not present a separate error term as in linear regression (additive error term) since $\lambda$ determines both the mean and variance of a Poisson random variable, it is recommended to use multiplicative errors to estimate the model (Mullahy, 1997). After treating the endogeneity of the accessibility variable, the final models were estimated using the ivpoisson tool of the Stata software version 13 with the option of multiplicative and robust errors. The final models and their results are presented in the results section of the paper.

One of the problems frequently encountered in regression models with spatial nature data is neglecting spatial dependence (LeSage and Pace, 2009). The spatial dependence leads to a simultaneity bias and compromises the consistency of the estimated coefficients. To evaluate the spatial dependence of the models, Moran's I was calculated for the three models' residuals using the two types of neighbourhood matrix (rook and queen) of first and second order. The Moran's I values found were quite low $(I \leq 0.033)$, indicating that there is no need to use spatial models.

\section{Descriptive Statistics}

The descriptive statistics of the number of activities performed are presented in Tables 1 and 2. On average, individuals perform 1.1 activities per day, with the average participation in mandatory activities equalling 0.78 and discretionary activities 0.18 . Approximately $3 \%$ of the sample participates in more than three activities. 
Luz, G., Barboza, M. H. C., Portugal, L., Giannotti, M., van Wee, B. (2022). Does better accessibility help to reduce social exclusion? Evidence from the city of São Paulo, Brazil. Transportation Research Part A: Policy and Practice, 166, 186-217. https://doi.org/10.1016/i.tra.2022.10.005

Regarding mandatory trips (work and study), 43.3\% did not participate in any of them on the day before the OD survey, and $39.64 \%$ participated in one mandatory activity. The vast majority of the sample (83.73\%) did not perform any discretionary trips on the day before the survey.

Table 1 - Univariate analysis of Dependent Variables

\begin{tabular}{lccccccccc}
\hline Activity Frequency & Mean & Std.Dev & Min & Q1 & Median & Q3 & Max & IQR & N.Valid \\
\hline Total activities & 1.10 & 1.05 & 0 & 0 & 1 & 1 & 13 & 1 & 47,167 \\
Mandatory/Fixed Activities & 0.78 & 0.86 & 0 & 0 & 1 & 1 & 13 & 1 & 47,167 \\
Discretionary/Flexible Activities & 0.18 & 0.44 & 0 & 0 & 0 & 0 & 7 & 0 & 47,167 \\
\hline
\end{tabular}

Table 2 - Distribution of Dependent Variables

\begin{tabular}{lrr}
\hline Total activities & $\mathbf{n}$ & \\
\hline 0 & 13,202 & 27.99 \\
1 & 23,152 & 49.09 \\
2 & 5,861 & 12.43 \\
3 & 3,557 & 7.54 \\
$>3$ & 1,395 & 2.96 \\
\hline
\end{tabular}

\begin{tabular}{lrr}
\hline Mandatory/Fixed Activities & \multicolumn{2}{c}{$\%$} \\
\hline 0 & 20,421 & 43.30 \\
1 & 18,696 & 39.64 \\
2 & 6,554 & 13.90 \\
3 & 992 & 2.10 \\
$>3$ & 504 & 1.07 \\
\hline
\end{tabular}

\begin{tabular}{lrr}
\hline Discretionary/Flexible Activities & $\mathbf{n}$ & \\
\hline 0 & 39495 & 83.73 \\
1 & 6914 & 14.66 \\
2 & 652 & 1.38 \\
3 & 74 & 0.16 \\
$>3$ & 32 & 0.07 \\
\hline
\end{tabular}


Luz, G., Barboza, M. H. C., Portugal, L., Giannotti, M., van Wee, B. (2022). Does better accessibility help to reduce social exclusion? Evidence from the city of São Paulo, Brazil. Transportation Research Part A: Policy and Practice, 166, 186-217. https://doi.org/10.1016/i.tra.2022.10.005

Table 3 characterises the sample according to sociodemographic variables. Figures 4, 5, 6, and 7 depict the spatial distribution of accessibility, income, social vulnerability, and self-declared black people in São Paulo, respectively. These figures reveal the city's racial, economic, and social segregation. While most people living in the centre are wealthier, white and less socially vulnerable, on the city's outskirts are the poorer, black and more vulnerable. According to the TRSE literature, the transport disadvantage is not equally or randomly distributed across society but follows the well-established lines of structural social inequality (Ureta, 2008; Lucas, 2011; Bocarejo and Hernandez, 2012; Jaramillo et al., 2012; Xiao et al., 2018). Locations with the worst levels of transport disadvantage are also those with the worst socioeconomic conditions (Jaramillo et al., 2012; Xiao et al., 2018).

A

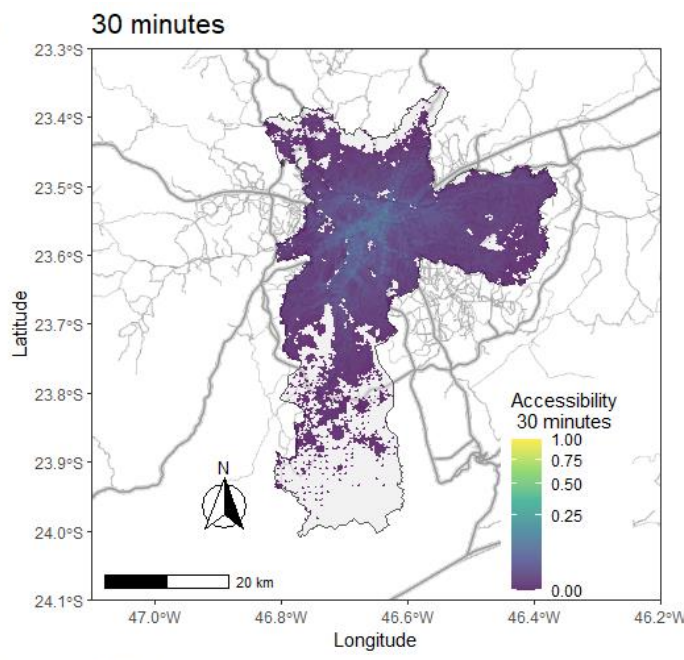

C

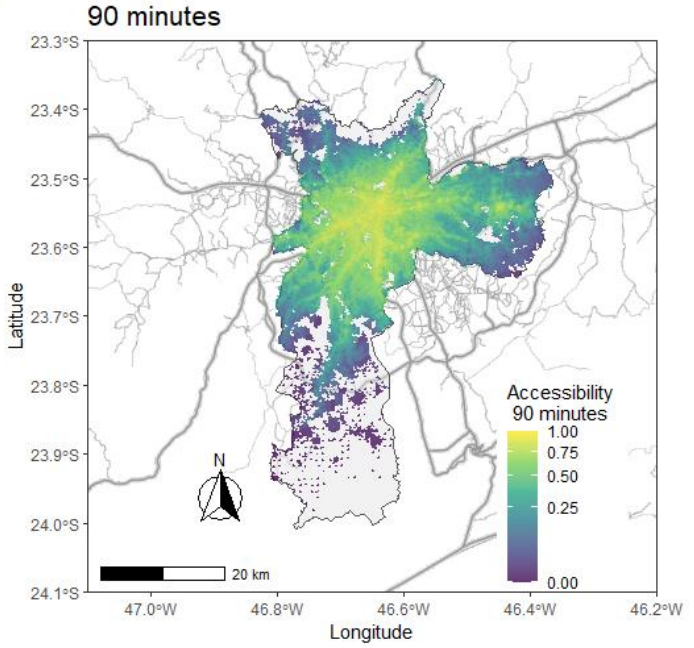

B

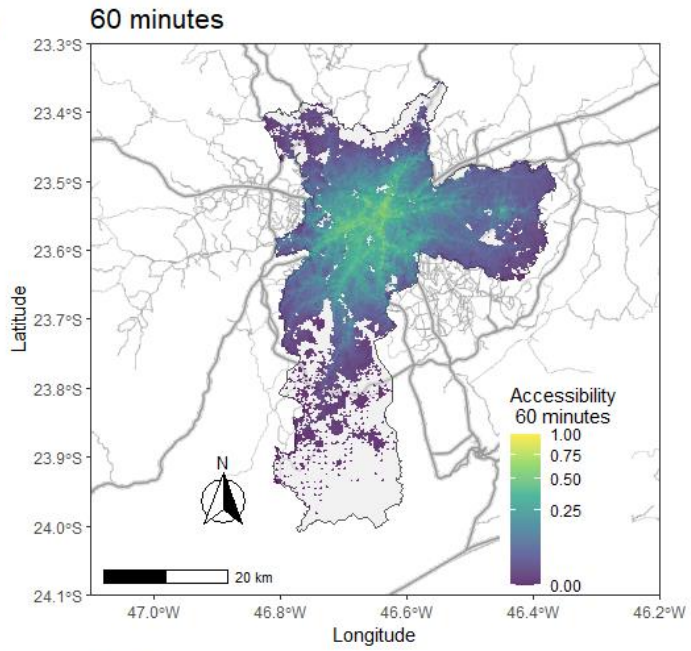

D

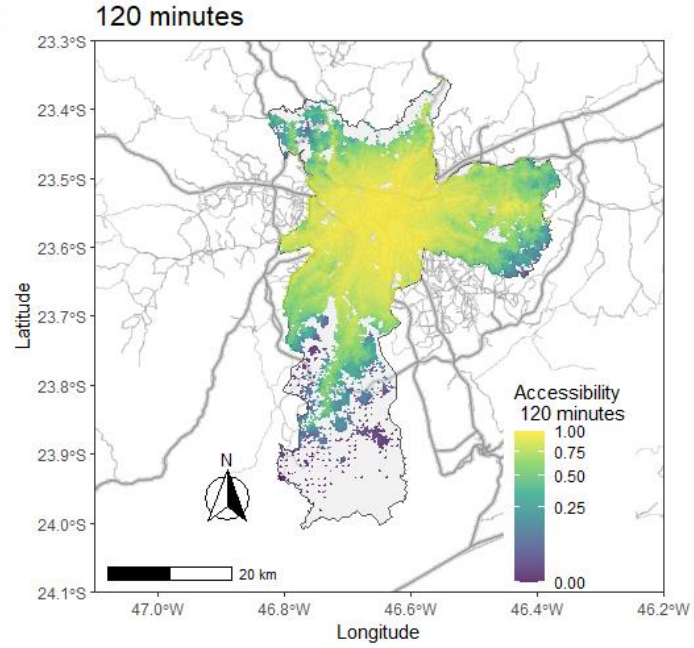

Figure 4 - Spatial distribution of accessibility measures

Table 3 -Characterisation of the sample sociodemographics

\begin{tabular}{llllllll}
\hline $\begin{array}{l}\text { Monthly Income per capita } \\
\text { (minimum wage of } U \$ \text { 285) }\end{array}$ & & $\%$ & Gender & & \% \\
\hline
\end{tabular}


Luz, G., Barboza, M. H. C., Portugal, L., Giannotti, M., van Wee, B. (2022). Does better accessibility help to reduce social exclusion? Evidence from the city of São Paulo, Brazil. Transportation Research Part A: Policy and Practice, 166, 186-217. https://doi.org/10.1016/i.tra.2022.10.005

\begin{tabular}{|c|c|c|c|c|c|}
\hline 0 & 385 & 0.82 & 0 - Male & 21,625 & 45.85 \\
\hline$<0.5$ & 3,175 & 6.73 & 1 - Female & 25,542 & 54.15 \\
\hline $0.5-1$ & 10,249 & 21.73 & & & \\
\hline $1-2$ & 14,662 & 31.09 & Employment Status & $n$ & $\%$ \\
\hline $2-3$ & 7,215 & 15.30 & 1 - Has a regular job & 24,175 & 51.25 \\
\hline $3-4$ & 4,089 & 8.67 & 2 - Do odd-jobs & 2,415 & 5.12 \\
\hline $4-5$ & 2,499 & 5.30 & 3 - On sick leave & 291 & 0.62 \\
\hline $5-10$ & 4,069 & 8.63 & 4-Retired/Pensioner & 8,320 & 17.64 \\
\hline \multirow[t]{2}{*}{$>10$} & 824 & 1.75 & 5 - Unemployed & 4,579 & 9.71 \\
\hline & & & 6 - Never worked & 166 & 0.35 \\
\hline Age Group & $n$ & $\%$ & 7 - Housewife & 3,090 & 6.55 \\
\hline $13-18$ & 2,950 & 6.25 & 8 - Student & 4,131 & 8.76 \\
\hline $18-29$ & 9,082 & 19.25 & & & \\
\hline $30-64$ & 26,714 & 56.64 & Study Status & $n$ & $\%$ \\
\hline $65-75$ & 4,915 & 10.42 & $1-$ No & 40,427 & 85.71 \\
\hline \multirow[t]{2}{*}{+75} & 3,506 & 7.43 & 3 - Primary/Elementary & 1,232 & 2.61 \\
\hline & & & 4 - Secondary/Middle & 1,925 & 4.08 \\
\hline Educational Level & $n$ & $\%$ & 5 - Higher/University & 3,038 & 6.44 \\
\hline 1 - Non-Literate/Incomplete Primary I & 3,071 & 6.51 & 6 - Other & 545 & 1.16 \\
\hline $\begin{array}{l}2 \text { - Elementary I Complete / } \\
\text { Incomplete Secondary II }\end{array}$ & 4,986 & 10.57 & & & \\
\hline $\begin{array}{l}3 \text { - Elementary II Complete / Middle } \\
\text { School }\end{array}$ & 6,365 & 13.49 & $\begin{array}{l}\text { Number of people in the } \\
\text { family }\end{array}$ & $n$ & $\%$ \\
\hline $\begin{array}{l}4 \text { - Secondary Complete / Higher } \\
\text { Education Incomplete }\end{array}$ & 16,463 & 34.90 & 1 & 4,299 & 9.11 \\
\hline \multirow[t]{2}{*}{5 - Higher Education Complete } & 16,282 & 34.52 & 2 & 13,096 & 27.77 \\
\hline & & & 3 & 13,119 & 27.81 \\
\hline Family status & $n$ & $\%$ & 4 & 10,049 & 21.31 \\
\hline 1 - Responsible person & 20,623 & 43.72 & 5 & 4,338 & 9.20 \\
\hline 2 - Spouse / Partner & 11,030 & 23.38 & 6 & 1,393 & 2.95 \\
\hline 3 - Child / Stepchild & 10,712 & 22.71 & 7 & 873 & 1.85 \\
\hline 4 - Other Relative & 4,045 & 8.58 & & & \\
\hline 5-Other Resident & 510 & 1.08 & Private vehicle per capita & $n$ & $\%$ \\
\hline 6 - Resident Employee & 242 & 0.51 & 0 & 16,315 & 34.59 \\
\hline \multirow[t]{2}{*}{7 - Relative of Resident Employee } & 5 & 0.01 & $<0.25$ & 2,497 & 5.29 \\
\hline & & & $0.25-0.50$ & 11,135 & 23.61 \\
\hline Individual Income & $n$ & $\%$ & $0.50-1.0$ & 12,187 & 25.84 \\
\hline Yes & 16,889 & 35.81 & $0.75-1.0$ & 737 & 1.56 \\
\hline No & 9,981 & 21.16 & $1.0-1.5$ & 4,500 & 9.54 \\
\hline Did not answer & 20,297 & 43.03 & $>1.5$ & 533 & 1.13 \\
\hline Paulista Social Vulnerability Index & $n$ & $\%$ & & & \\
\hline $\begin{array}{l}0 \text { - Does not live in a high social } \\
\text { vulnerability region }\end{array}$ & 42,777 & 90.69 & & & \\
\hline $\begin{array}{l}1 \text { - Lives in a high social vulnerability } \\
\text { region }\end{array}$ & 4,390 & 9.31 & & & \\
\hline
\end{tabular}


Luz, G., Barboza, M. H. C., Portugal, L., Giannotti, M., van Wee, B. (2022). Does better accessibility help to reduce social exclusion? Evidence from the city of São Paulo, Brazil. Transportation Research Part A: Policy and Practice, 166, 186-217. https://doi.org/10.1016/i.tra.2022.10.005

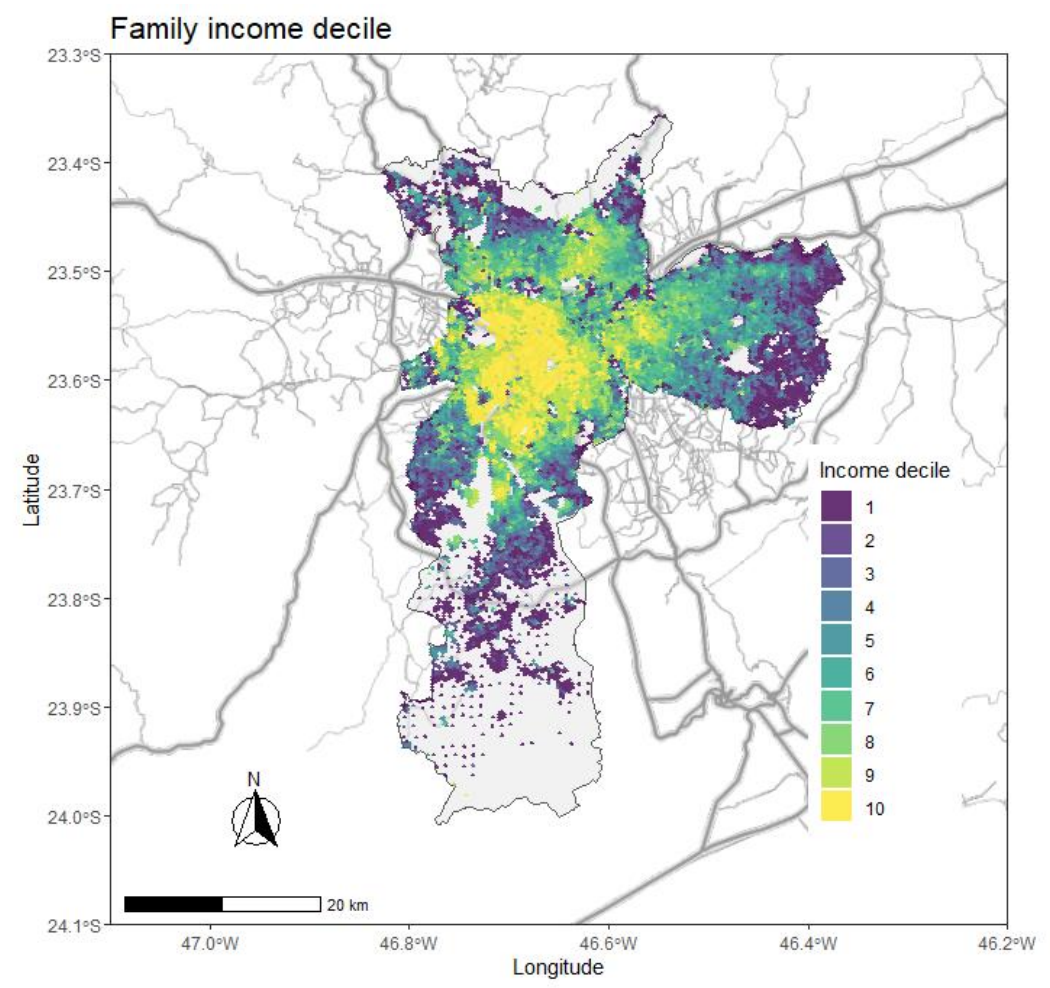

Figure 5 - Spatial distribution of family income

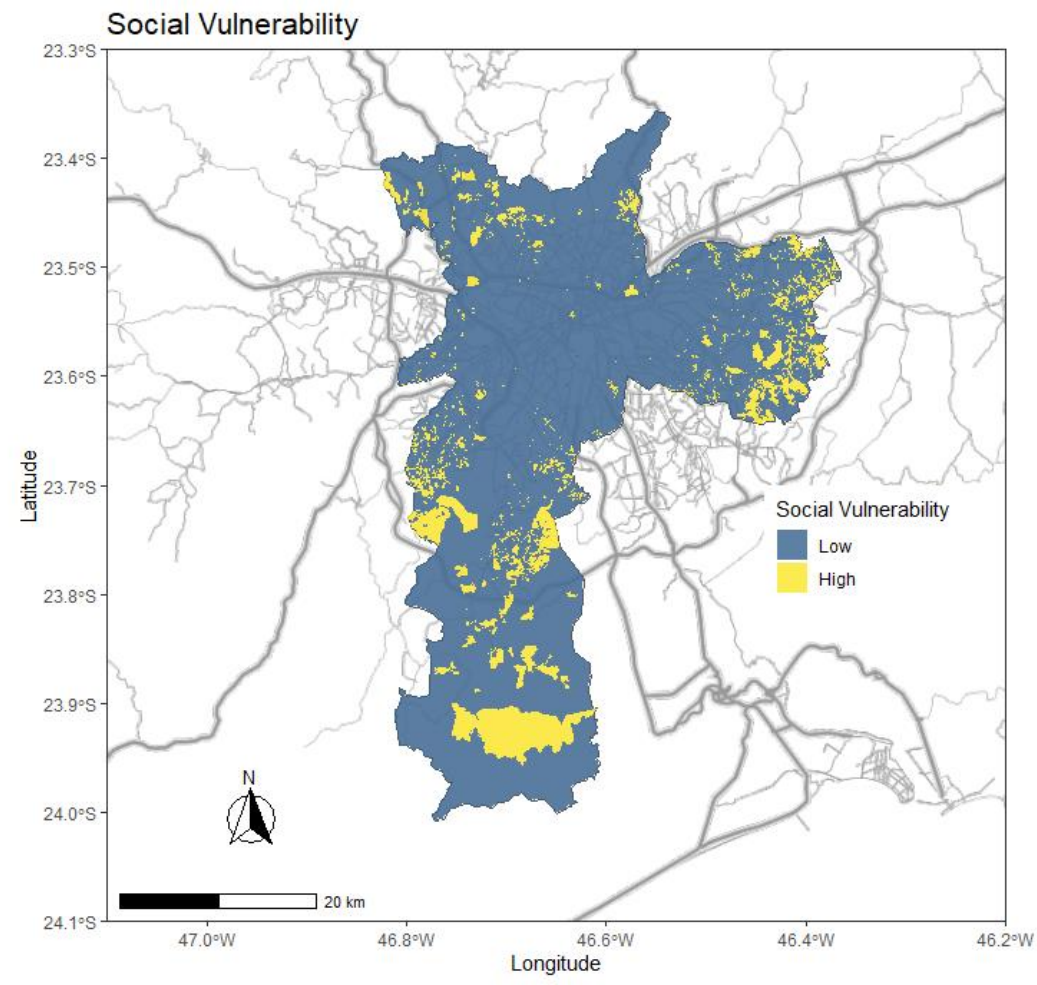

Figure 6 - Spatial distribution of social vulnerability 
Luz, G., Barboza, M. H. C., Portugal, L., Giannotti, M., van Wee, B. (2022). Does better accessibility help to reduce social exclusion? Evidence from the city of São Paulo, Brazil. Transportation Research Part A: Policy and Practice, 166, 186-217. https://doi.org/10.1016/i.tra.2022.10.005

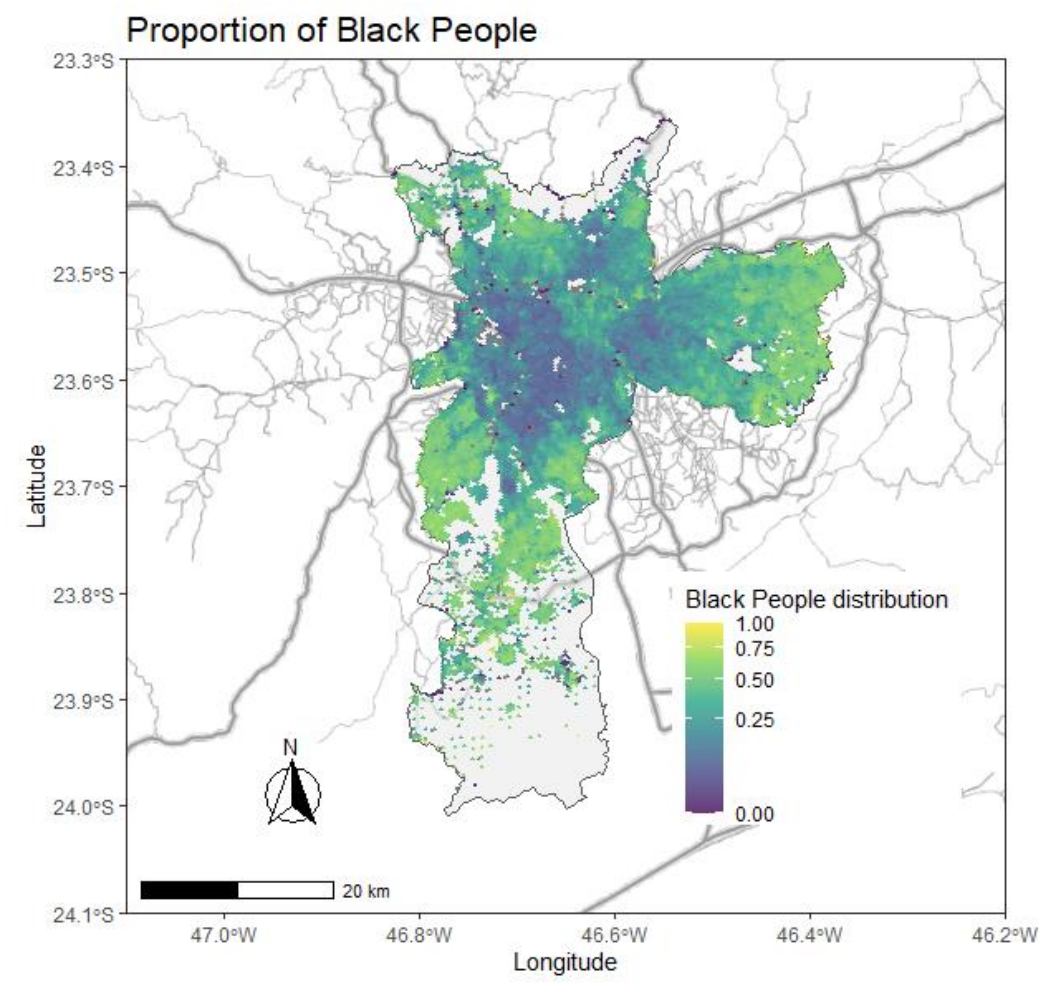

Figure 7 - Spatial distribution of self-declared black people in the city of São Paulo,

\section{Results and Discussion}

\subsection{Socio-demographics and Activity Participation}

Although we cannot infer a cause-effect relationship between the sociodemographic factors included in the model and the activity participation level, exploring the models' results for these variables can help us better understand the TRSE phenomenon (Table 4). 
Luz, G., Barboza, M. H. C., Portugal, L., Giannotti, M., van Wee, B. (2022). Does better accessibility help to reduce social exclusion? Evidence from the city of São Paulo, Brazil. Transportation Research Part A: Policy and Practice, 166, 186-217. https://doi.org/10.1016/i.tra.2022.10.005

Table 4 - Activity participation models after IV introduction

Total Activities $(\mathrm{n}=\mathbf{4 7 , 1 6 7 )}$

\begin{tabular}{|c|c|c|c|c|}
\hline Independent Variable & IRR & $\begin{array}{c}\text { Robust } \\
\text { Std. Error }\end{array}$ & $\mathbf{Z}$ & P-value \\
\hline Accessibility (90 minutes) & 1.448 & 0.063 & 5.92 & 0 \\
\hline Family per capita monthly income (in thousand reais) & 1.046 & 0.004 & 10.48 & 0 \\
\hline$(\text { Family per capita monthly income (in thousand reais) })^{\wedge} 2$ & 0.999 & 0.000 & -7.37 & 0 \\
\hline Age & 1.015 & 0.002 & 6.83 & 0 \\
\hline$(\mathrm{Age})^{\wedge} 2$ & 1.000 & 0.000 & -8.79 & 0 \\
\hline Family per capita private vehicles & 1.137 & 0.016 & 7.85 & 0 \\
\hline \multicolumn{5}{|l|}{ Gender (reference "Male") } \\
\hline Female & 0.988 & 0.010 & -1.13 & 0.257 \\
\hline Number of people in the family & 0.990 & 0.014 & -0.72 & 0.474 \\
\hline (Number of people in the family) ${ }^{\wedge} 2$ & 1.002 & 0.002 & 1.38 & 0.169 \\
\hline Proportion of self-declared black population in the region & 1.085 & 0.066 & 1.25 & 0.212 \\
\hline \multicolumn{5}{|l|}{ Study Status (reference "No") } \\
\hline Primary/Elementary & 2.394 & 0.035 & 24.98 & 0 \\
\hline Secondary/Middle & 2.203 & 0.030 & 26.33 & 0 \\
\hline Higher/University & 1.669 & 0.016 & 31.27 & 0 \\
\hline Other & 1.629 & 0.029 & 16.75 & 0 \\
\hline \multicolumn{5}{|l|}{ Employment status (reference "Has a regular job") } \\
\hline Does odd-jobs & 0.760 & 0.022 & -12.51 & 0 \\
\hline On sick leave & 0.338 & 0.092 & -11.8 & 0 \\
\hline Retired/Pensioner & 0.529 & 0.022 & -29.38 & 0 \\
\hline Unemployed & 0.469 & 0.030 & -25.06 & 0 \\
\hline Never worked & 0.311 & 0.155 & -7.52 & 0 \\
\hline Housewife & 0.553 & 0.035 & -16.88 & 0 \\
\hline
\end{tabular}

Mandatory Activities $(n=47,167)$

\begin{tabular}{ccccc}
\hline IRR & $\begin{array}{c}\text { Robust } \\
\text { Std. Error }\end{array}$ & $\mathbf{Z}$ & P-value & \\
\cline { 1 - 4 } 2.076 & 0.173 & 4.23 & 0.000 & $* * *$ \\
1.033 & 0.014 & 2.41 & 0.016 & $*$ \\
0.999 & 0.000 & -1.83 & 0.067 & \\
1.065 & 0.007 & 9.61 & 0.000 & $* * *$ \\
0.999 & 0.000 & -11.46 & 0.000 & $* * *$ \\
1.317 & 0.049 & 5.67 & 0.000 & $* * *$
\end{tabular}

$1.317 \quad 0.049$

$0.940 \quad 0.033$

1.502

0.975

1.288

0.042

0.005

0.192

\subsection{5}

3.784

2.632

3.539

0.096

0.068

0.040

0.111

$0.691 \quad 0.038$

0.062

0.073

0.146

0.045

0.191
0.038
0.220
0.074
0.051
0.477
0.064

$-1.91 \quad 0.056$

9.73
-5.37

1.32

$14.90 \quad 0.000$

$19.650 .000 \quad * * *$

$24.020 .000 \quad * *$

11.420 .000 *

$-9.690 .000 \quad * * *$

$\begin{array}{lll}-12.66 & 0.000 \quad * * *\end{array}$

$-35.40$

$-37.86-0.000 \quad *$

$\begin{array}{lll}-6.49 & 0.000 \quad * * *\end{array}$

$-26.010 .000 \quad * * *$
Discretionary Activities $(\mathrm{n}=47,167)$

\begin{tabular}{lccr}
\hline IRR & Robust \\
& Std. Error & Z & P-value \\
\hline
\end{tabular}

$1.745 \quad 0.183$

3.04

0.002

$\begin{array}{llll}1.126 & 0.010 & 11.44 & 0.000\end{array}$ ***

$\begin{array}{lllll}0.997 & 0.000 & -6.94 & 0.000 & * * *\end{array}$

$\begin{array}{lllll}1.012 & 0.005 & 2.24 & 0.025\end{array}$ *

$\begin{array}{llll}1.000 & 0.000 & -2.94 & 0.003\end{array}$

$\begin{array}{lllll}1.258 & 0.042 & 5.48 & 0.000\end{array}$ ***

$\begin{array}{lllll}0.939 & 0.030 & -2.08 & 0.038 & *\end{array}$

$\begin{array}{llll}0.937 & 0.015 & -4.24 & 0.000\end{array} * * *$

$\begin{array}{cccc}- & - & - & - \\ 0.791 & 0.185 & -1.27 & 0.206\end{array}$

$\begin{array}{llll}0.831 & 0.184 & -1.00 & 0.315\end{array}$

$\begin{array}{llll}1.097 & 0.154 & 0.60 & 0.550\end{array}$

$\begin{array}{llll}0.891 & 0.072 & -1.61 & 0.107\end{array}$

$\begin{array}{llll}1.038 & 0.119 & 0.31 & 0.753\end{array}$

$\begin{array}{llll}1.038 & 0.071 & 0.53 & 0.598\end{array}$

$\begin{array}{llll}0.896 & 0.182 & -0.61 & 0.544\end{array}$

$\begin{array}{llll}1.657 & 0.046 & 10.91 & 0.000\end{array} * * *$

$\begin{array}{lllll}1.387 & 0.071 & 4.59 & 0.000\end{array}$ ***

$\begin{array}{llll}1.040 & 0.311 & 0.13 & 0.900\end{array}$

$1.828 \quad 0.078 \quad 7.70 \quad 0.000 \quad * * *$ 
Luz, G., Barboza, M. H. C., Portugal, L., Giannotti, M., van Wee, B. (2022). Does better accessibility help to reduce social exclusion? Evidence from the city of São Paulo, Brazil. Transportation Research Part A: Policy and Practice, 166, 186-217. https://doi.org/10.1016/i.tra.2022.10.005

Student
ve in a high social vulnerability region (reference "No")

Yes

Level of Education (reference "Higher Education Complete")

Non-Literate/Incomplete Primary

Elementary I Complete/Incomplete Elementary II

Elementary II Complete/High School Incomplete

High School Complete / Higher Education Incomplete

Individual income (reference "Did not answer")

Yes

No

Populational Density

Family status (reference "Responsible person")

Spouse / Partner

Child / Stepchild

Other Relative

Other Resident

Resident Employee

Relative of Resident Employee

Living with a dependent child (under 18 years old)

Living with a dependent elderly person (over 65 yeards old)

Constant

Note: (.) $p<0.1 ;(*) p<0.05 ;(* *) p<0.01 ;(* * *) p<0.001$

\begin{tabular}{|c|c|c|c|c|c|c|c|c|c|c|c|c|c|c|}
\hline 0.630 & 0.029 & -16.07 & 0 & $* * *$ & 0.397 & 0.038 & -24.46 & 0.000 & $* * *$ & 0.816 & 0.121 & -1.68 & 0.093 & \\
\hline 0.940 & 0.020 & -3.08 & 0.002 & $* *$ & 0.901 & 0.044 & -2.37 & 0.018 & $*$ & 0.776 & 0.069 & -3.69 & 0.000 & $* * *$ \\
\hline 0.698 & 0.030 & -12.01 & 0 & $* * *$ & 0.807 & 0.103 & -2.09 & 0.036 & $*$ & 0.489 & 0.075 & -9.53 & 0.000 & $* * *$ \\
\hline 0.771 & 0.025 & -10.48 & 0 & $* * *$ & 0.888 & 0.084 & -1.41 & 0.159 & & 0.591 & 0.062 & -8.48 & 0.000 & $* * *$ \\
\hline 0.797 & 0.022 & -10.52 & 0 & $* * *$ & 0.865 & 0.061 & -2.37 & 0.018 & $*$ & 0.602 & 0.059 & -8.58 & 0.000 & $* * *$ \\
\hline 0.866 & 0.013 & -10.73 & 0 & $* * *$ & 0.904 & 0.041 & -2.47 & 0.013 & $*$ & 0.675 & 0.034 & -11.62 & 0.000 & $* * *$ \\
\hline 1.096 & 0.011 & 8.6 & 0 & $* * *$ & - & - & - & - & & 1.350 & 0.030 & 10.03 & 0.000 & $* * *$ \\
\hline 0.964 & 0.029 & -1.27 & 0.204 & & - & - & - & - & & 1.024 & 0.070 & 0.34 & 0.735 & \\
\hline 1.001 & 0.000 & 2.23 & 0.026 & $*$ & 1.002 & 0.002 & 1.14 & 0.254 & & 1.003 & 0.001 & 2.17 & 0.030 & $*$ \\
\hline 0.862 & 0.014 & -10.38 & 0 & $* * *$ & 0.784 & 0.040 & -6.03 & 0.000 & $* * *$ & 0.777 & 0.036 & -7.00 & 0.000 & $* * *$ \\
\hline 0.769 & 0.018 & -14.59 & 0 & $* * *$ & 0.646 & 0.044 & -10.02 & 0.000 & $* * *$ & 0.678 & 0.055 & -7.02 & 0.000 & $* * *$ \\
\hline 0.647 & 0.025 & -17.17 & 0 & $* * *$ & 0.604 & 0.081 & -6.21 & 0.000 & $* * *$ & 0.550 & 0.066 & -9.14 & 0.000 & $* * *$ \\
\hline 0.817 & 0.039 & -5.15 & 0 & $* * *$ & 0.622 & 0.057 & -8.32 & 0.000 & $* * *$ & 0.992 & 0.116 & -0.07 & 0.947 & \\
\hline 0.277 & 0.108 & -11.88 & 0 & $* * *$ & 0.054 & 0.300 & -9.74 & 0.000 & $* * *$ & 0.866 & 0.173 & -0.83 & 0.407 & \\
\hline 0.291 & 0.574 & -2.15 & 0.032 & $*$ & 0.288 & 0.560 & -2.23 & 0.026 & $*$ & & & & & $* * *$ \\
\hline 1.358 & 0.014 & 21.99 & 0 & $* * *$ & 1.508 & 0.041 & 10.08 & 0.000 & $* * *$ & 1.057 & 0.042 & 1.330 & 0.183 & \\
\hline 1.043 & 0.016 & 2.6 & 0.009 & $* *$ & 0.798 & 0.038 & -6.00 & 0.000 & $* * *$ & 1.239 & 0.045 & 4.770 & 0.000 & $* * *$ \\
\hline 0.798 & 0.080 & -2.82 & 0.005 & $* *$ & 0.097 & 0.230 & -10.14 & 0.000 & $* * *$ & 0.111 & 0.216 & $\begin{array}{c}- \\
10.200\end{array}$ & 0.000 & $* * *$ \\
\hline
\end{tabular}


Luz, G., Barboza, M. H. C., Portugal, L., Giannotti, M., van Wee, B. (2022). Does better accessibility help to reduce social exclusion? Evidence from the city of São Paulo, Brazil. Transportation Research Part A: Policy and Practice, 166, 186-217. https://doi.org/10.1016/i.tra.2022.10.005

The per capita family income variable presented a quadratic relationship with the total, mandatory and discretionary activities variables. The quadratic relationship between the per capita family income variable and the number of total, mandatory and discretionary activities shows that the increase in income among individuals with lower per capita family income has a greater impact on activity participation. This impact decreases as income increases.

The individual income variable was included only in the total activities and discretionary activities models since simultaneity issues could emerge in the mandatory activities model. Only the "Yes" category presented statistical significance in both models in which it was included. On average, people who have an individual income participate in $9.63 \%$ more total activities than those who did not declare whether they have income or not, and in $35.02 \%$ more discretionary activities also compared to the reference category. These results are consistent with the TRSE literature indicating that poverty and low income represent risk factors for TRSE (Ureta, 2008; Lucas, 2011; Bocarejo and Oviedo, 2012; Jaramillo et al., 2012; Kamruzzaman and Hine, 2012; Walks, 2018; Luz and Portugal, 2021).

The three models pointed out that the age variable has a quadratic association with activity participation. As age increases, the activity participation rate increases for all types of activity up to a certain threshold, where increasing age leads to a reduction in the number of activities undertaken by the individual. The age at which individuals participate in more activities is approximately 37 years for total activities, 38 years for mandatory activities and 40 years for discretionary activities. For the elderly, the TRSE literature points out that their physical and cognitive difficulties in using public transport may put them at risk of social exclusion (Denmark, 1998; Engels and Liu, 2011; Shergold and Parkhurst, 2012; Luz and Portugal, 2021). On the other hand, younger individuals often lack the independence and safety to travel alone or are not allowed to drive and, therefore, have their ability to participate in activities limited (Denmark, 1998; Kenyon et al., 2002; Luz and Portugal, 2021).

The number of family per capita private vehicles positively correlates with activity participation. The results align with the TRSE literature, which points out that households with fewer cars participate in fewer activities. The impact of lack of a car is even more significant in cardependent societies (Hine, 2004; Delbosc and Currie, 2011; Jaramillo et al., 2012; Kamruzzaman and Hine, 2012; Shergold and Parkhurst, 2012; Mattioli, 2014). 
Luz, G., Barboza, M. H. C., Portugal, L., Giannotti, M., van Wee, B. (2022). Does better accessibility help to reduce social exclusion? Evidence from the city of São Paulo, Brazil. Transportation Research Part A: Policy and Practice, 166, 186-217. https://doi.org/10.1016/i.tra.2022.10.005

The gender variable was only statistically significant in the mandatory and discretionary activities model. Women participate in $6.02 \%$ and $6.10 \%$ less mandatory and discretionary activities than men, respectively. Although the gender variable is not statistically significant in the total activities model, people in the category Spouse / Partner, composed mainly of women, participate in $13.80 \%$ fewer activities than the reference category Responsible person, composed chiefly of men. We also found that retired individuals, unemployed individuals or individuals who have never worked participate in less total and mandatory activities but in more discretionary activities than those with a regular job. It may indicate that time availability is crucial for participation in non-discretionary activities (Fransen et al., 2018; Landau et al., 1982).

The number of family members is associated with the mandatory and discretionary activity participation level. The relationship between the number of family members and participation in activities is quadratic for mandatory activities. The number of mandatory activities in which the individual participates increases as the number of people in the family increases, reaching the inflexion point at eight members. The variation in the rate of increase in discretionary activities is constant. One more individual in the family is associated with $6.29 \%$ lower participation in discretionary activities. These findings may suggest that the more people in the family, the less the individual's need for social interaction since they can partially fulfil it at home.

We also found that individuals over 18 and under 65 years old who live with a dependent child participate in $50.81 \%$ more mandatory activities than those who do not. At the same time, this group of individuals who live with a dependent elderly person participates in $20.20 \%$ fewer mandatory activities and $23.88 \%$ more discretionary activities. These results may indicate that individuals with a dependent child must work to maintain their kids. Having children does not necessarily compromise the time available to work since the children will be at school during the same period. On the other hand, those who live with a dependent elderly person need to be present throughout the day with her since the elderly do not have an occupation for the whole day as kids do. In addition, seniors often have pensions and participate in more discretionary activities than those who work. It may be that the greater participation in discretionary activities by those who live with a dependent elderly person is accompanying such individuals.

The proportion of self-declared black people was not significant in the three models. The results may suggest that the metric adopted is inadequate to capture difficulties in activity participation due to an individual's race, possibly because we did not have the individual's race but only the share for each neighbourhood. Although we did not find statistical significance, past work 
Luz, G., Barboza, M. H. C., Portugal, L., Giannotti, M., van Wee, B. (2022). Does better accessibility help to reduce social exclusion? Evidence from the city of São Paulo, Brazil. Transportation Research Part A: Policy and Practice, 166, 186-217. https://doi.org/10.1016/i.tra.2022.10.005

conducted in São Paulo's context has pointed out that travel times, costs and transfers have a greater impact on job accessibility among blacks than among whites and that race is a factor that matters even more than social class in post-colonial societies marked by slavery, such as Brazil (Bittencourt and Giannotti, 2021).

The models indicate that people who study, on average, perform more total and mandatory activities than those who do not study. In addition, the activity participation level decreases as the schooling level increases. Regarding the employment status, all categories, on average, participate in fewer activities than individuals who work regularly. In the discretionary activities model, Retired and pensioners, people without work and housewives present a higher level of participation than those who work regularly and study. People who live in socially vulnerable regions participate in fewer total, mandatory and discretionary activities. The number is especially high for discretionary activities, in which those who live in vulnerable areas participate in $22.39 \%$ fewer activities than those who do not. This finding is aligned with TRSE literature (Lucas, 2011; Ureta, 2008).

The lower the level of education, the fewer total and discretionary activities the individual engages in. These results are consistent with the TRSE literature, which indicates that illiterate or cognitively impaired individuals often find using public transport confusing (Denmark, 1998; Luz and Portugal, 2021). It is worth noting that low educational level is correlated with the category of youth and low-income adults.

The population density was statistically significant for the total and discretionary activity models. Despite the small magnitude, this result is in line with other studies (Cheng et al., 2019; Merlin, 2015). The literature suggests that denser locations make the urban environment livelier and more attractive to undertake trips on foot(Ewing et al., 1996; Ma et al., 2018). In addition, denser places may be associated with less need to use private vehicles to carry out activities.

\subsection{The relationship between Accessibility and Activity Participation}

The relationships between accessibility measured by the cumulative opportunities measure (CUM) with a threshold of 90-minute travel time by public transport and the number of total, mandatory and discretionary activities participated in were analysed with a maximum likelihood estimation of a Poisson regression model. As mentioned earlier, other travel times by public 
Luz, G., Barboza, M. H. C., Portugal, L., Giannotti, M., van Wee, B. (2022). Does better accessibility help to reduce social exclusion? Evidence from the city of São Paulo, Brazil. Transportation Research Part A: Policy and Practice, 166, 186-217. https://doi.org/10.1016/i.tra.2022.10.005

transport were tested; however, the accessibility measure with the cut-off time of 90 minutes was the one that best explained the dependent variable (higher residual deviance after its introduction) in all three models. The instrumental variable strategy was used to overcome any possible endogeneity issue caused by omitted variables and, therefore, infer causality between accessibility and activity participation.

Although the cumulative opportunities measure of accessibility does not capture several nuances that may influence individuals' ability to engage in activities, the models indicated that it still has a causal effect on activity participation. It means that higher levels of accessibility cause greater activity participation, regardless of the type of activity.

The three estimated models (Table 4) indicate that accessibility is highly significant, at least at the $99 \%$ significance level. However, the impact of accessibility is not the same for the three categories of activities. The increment of one percentage point in the number of jobs that the individual can access by public transport within 90 minutes causes a $0.45 \%$ increase in the total activities carried out, $1.08 \%$ in the mandatory activities, and $0.75 \%$ in the number of discretionary activities, on average. On average, one standard deviation on accessibility (0.24) increases $10.75 \%$ in total activities, $25.81 \%$ in mandatory activities, and $17.89 \%$ in discretionary activities. It means that a transportation policy or project that provides a 24 percentage point increase in the number of jobs an individual can access in the city of São Paulo will cause an average increase in individuals' participation of $10.75 \% \%$ in total activities, $25.81 \%$ in mandatory activities, and $17.89 \%$ in discretionary activities. It is worth noting that the impact of accessibility on the total number of activities is not equal to the sum of the impacts on the mandatory and discretionary activities models because the total activities category includes other types of activities not covered by the other categories.

The effect of accessibility on activity participation is more prominent in the models in which the instrumental variable was included than in the model in which endogeneity was not addressed (Appendix B). In models before the introduction of the instrumental variable, a one percentage point increase in the number of accessible jobs by public transport, within 90 minutes, is up to three times smaller for total activities $(0.16 \%)$, ten times smaller for mandatory activities $(0.10 \%)$ and two times smaller $(0.38 \%)$ for discretionary activities, than the model that addresses endogeneity. 
Luz, G., Barboza, M. H. C., Portugal, L., Giannotti, M., van Wee, B. (2022). Does better accessibility help to reduce social exclusion? Evidence from the city of São Paulo, Brazil. Transportation Research Part A: Policy and Practice, 166, 186-217. https://doi.org/10.1016/i.tra.2022.10.005

These findings suggest that a large part of the studies which have assessed the relationship between accessibility and participation in activities may be underestimated. Moreover, impact evaluations and public policies based on accessibility may also have their benefits underestimated. The difference between the effect of accessibility in the models in which endogeneity was ignored and those in which the instrumental variable was introduced seems to follow the literature findings in general. Much of the literature found that discretionary activities are more elastic to variations in accessibility than the other types of activities. Perhaps this finding is more common because of the smaller bias generated by the endogeneity for this kind of activity.

Although the relative impact of accessibility is higher for mandatory-type activities, the absolute impact on the number of activities is higher for the total activities category, followed by mandatory and discretionary activities. This result goes against many studies on the relationship between accessibility and trip making, suggesting that trip making and activity participation for discretionary purposes are more elastic than mandatory. Nevertheless, the sample characteristics may be influencing the results. The São Paulo OD Survey registers only trips made during weekdays, when the proportion of activities for discretionary purposes is limited. Also, although the São Paulo OD Survey captures the trip chaining, we only consider the trip's primary purpose in our analysis. In this sense, it may be possible that the impact of accessibility on discretionary activities is greater than we found due to the sample restrictions. The findings suggest that greater accessibility levels cause greater participation in mandatory activities.

Considering that individuals participate in only one employment activity per day, it is possible that as an individual's accessibility level increases, individuals may move from 0 to 1 mandatory activity performed. In this way, we can speculate that higher levels of accessibility may be associated with a higher probability of getting a job. This hypothesis was confirmed by Bastiaanssen et al. (2021) in the Great Britain context. Likewise, we can speculate that individuals with low levels of accessibility may have limited access to education. In other words, low levels of accessibility can considerably restrict an individual's life chances.

Figure 8 shows the relationship between accessibility and activity participation. The intercepts in the plot are the constants of the models in Table 4. Although the curve shape of the models fits the activity participation distribution very well, it fails to capture the diminishing effect on participation for the highest levels of accessibility suggested by Martens (2016b) and Allen and Farber (2020). A quadratic specification and a logistic transformation of the accessibility variable 
Luz, G., Barboza, M. H. C., Portugal, L., Giannotti, M., van Wee, B. (2022). Does better accessibility help to reduce social exclusion? Evidence from the city of São Paulo, Brazil. Transportation Research Part A: Policy and Practice, 166, 186-217. https://doi.org/10.1016/i.tra.2022.10.005

were tested in order to capture this effect; however, without success. According to our model, participation increases exponentially (albeit at a minimal rate) when accessibility increases, which contradicts the widely held belief in the literature that improvements in the low end of accessibility should result in larger increases in participation. This finding is similar to Fransen et al. (2018)'s findings for the accessibility-activity participation curve.

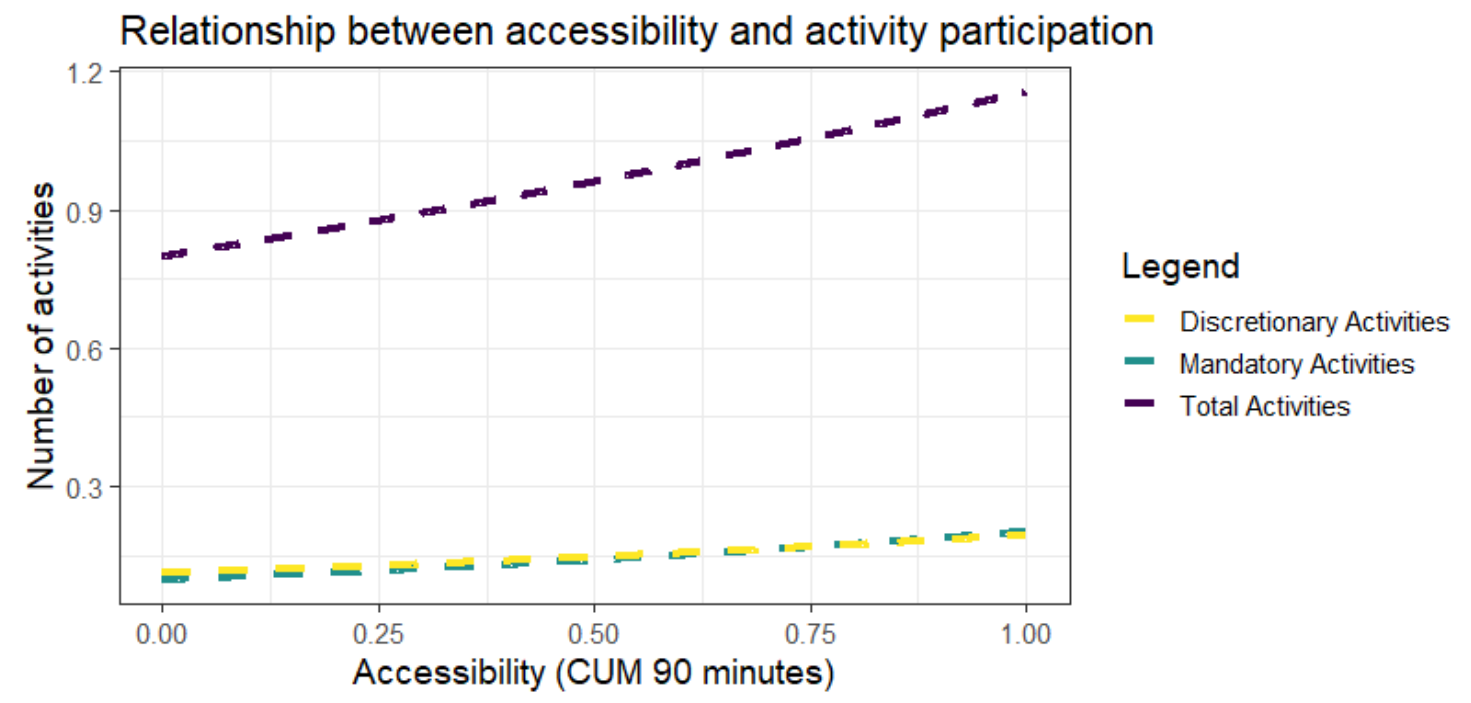

Figure 8 - The shape of accessibility-activity participation relationship

Some possible explanations for the shape of the curve found can be raised. Even though figure 8 suggests an exponential relationship between accessibility and participation in activities, the slope increases at a minimal rate, fitting almost a linear relationship between the variables. This may suggest that accessibility and activity participation have a linear relationship, as assumed by most of the studies about the theme. Another possible explanation is that the asymptotic nature of the relationship between accessibility and activity participation is being hidden by cumulative opportunities accessibility measure, which equates accessibility over large areas of the central part of the city. It is worth noting that the city of São Paulo is considerably larger than other cities in which similar studies have been carried out. A third explanation for our results may be the characteristics of the sample. The São Paulo OD survey collects data for a 24hour period. Perhaps a more apparent pattern of a sigmoid curve or a curve with diminishing gains in activity participation would be obtained using a more extended time window, such as a week. 
Luz, G., Barboza, M. H. C., Portugal, L., Giannotti, M., van Wee, B. (2022). Does better accessibility help to reduce social exclusion? Evidence from the city of São Paulo, Brazil. Transportation Research Part A: Policy and Practice, 166, 186-217. https://doi.org/10.1016/i.tra.2022.10.005

Finally, the individuals' gains from greater accessibility levels may be underestimated. Individuals may be interested not only in the number of activities they participate in but also in the quality of those activities. It is unlikely that individuals will participate in more than one work or education activity because of increased levels of accessibility. However, this individual may get a better-paid job or access better quality education because of higher levels of accessibility, as indicated by Pizzol et al. (2021). As a result, all else being equal, a better level of accessibility is likely to allow people to obtain more benefits from participating in activities.

\section{Conclusions}

The relationship between accessibility, participation in activities, and risk of social exclusion is complex. Physical accessibility is shaped by four components which, in turn, are composed of numerous sub-components. In addition, physical accessibility conditions interact with the individual's virtual accessibility, the political, economic, and social environment in which they are inserted, and their access needs and choice alternatives. The interaction of all these elements may enable the individuals to travel to and participate in the desired activity or create impediments to their participation. The latter situation suggests that individuals are at risk of TRSE.

Most studies on assessing TRSE or transport equity assume that more accessibility leads to greater participation in activities and, consequently, lower risk of TRSE. However, we verified that the available empirical evidence on this relationship is insufficient to validate this assumption. The 38 studies selected from a systematic literature review on the subject do not point to a consensus. Furthermore, through the systematic literature review, we identified some gaps that we addressed in the empirical part of the paper. The first gap was that few studies investigated the relationship between accessibility and participation in activities from TRSE and equity perspectives. A large part of the studies apply aggregate accessibility measures by zone and do not adequately control for interpersonal characteristics of individuals. The vast majority of studies on the subject were conducted in a Global North context, where cities and social realities are entirely different from the Global South's unequal cities. Finally, none of the studies assessed the causality of accessibility measures on activity participation, restricting themselves only to the correlational relationship. 
Luz, G., Barboza, M. H. C., Portugal, L., Giannotti, M., van Wee, B. (2022). Does better accessibility help to reduce social exclusion? Evidence from the city of São Paulo, Brazil. Transportation Research Part A: Policy and Practice, 166, 186-217. https://doi.org/10.1016/i.tra.2022.10.005

We proposed three Poisson regression models associated with an instrumental variable identification strategy to fill the gaps identified in the literature. The three models revealed a highly significant strong correlation between individuals' accessibility level and their actual participation in total, mandatory and discretionary activities. We tested four different time thresholds and different specifications and transformations for the accessibility measure. We found that the one that best explains the dependent variable variability is the linear cumulative opportunities measured with a 90-minute travel time threshold by public transport.

Our results suggest that low accessibility levels may severely restrict individuals' life chances and shed light on the importance of including the accessibility dimension in transport policies. Previous studies and public policies based on accessibility that ignored the endogeneity in the relationship between accessibility and activity participation may have underestimated their results in terms of activity participation up to ten times. Furthermore, our findings point out that accessibility, even accounting only for transport and land use components, such as CUM measure, is critical in enhancing individuals' capabilities. We also consider that individuals may be interested not only in the number of activities they participate in but also in the quality of those activities. In this sense, the gains provided by accessibility improvements may be much higher than those estimated.

The three models we proposed fit the distribution of the dependent variables very well. However, the models failed to capture the diminishing increase in participation for individuals with high accessibility levels. We speculate three possible explanations for our findings. Poisson regression suggests an exponential relationship between independent and dependent variables. However, our models indicate that the exponential relationship between accessibility and activity participation is almost nonexistent and that the relationship between both variables approaches a linear relationship. In this sense, the first explanation for our results is that accessibility and activity participation may actually have a linear relationship. Second, the asymptotic relationship between accessibility and activity participation is hidden by how accessibility was measured. Third, a 24-hour data collection period is too short to reveal a sigmoid or a curve with diminishing gains in activity participation.

Although we cannot infer causality from the relationship between activity participation and socioeconomic and locational variables, our results proved consistent with the TRSE literature. Only the race variable had divergent results from the theory. Further research using proper metrics to capture difficulties in activity participation due to an individual's race is needed. 
Luz, G., Barboza, M. H. C., Portugal, L., Giannotti, M., van Wee, B. (2022). Does better accessibility help to reduce social exclusion? Evidence from the city of São Paulo, Brazil. Transportation Research Part A: Policy and Practice, 166, 186-217. https://doi.org/10.1016/i.tra.2022.10.005

Although this paper has advanced compared to previous studies in this field, further research lines may stem from it. A longer time horizon in data collection may also capture fluctuations in activity participation patterns. Including weekend trip-making information in OD Survey may help better estimate the relationship between accessibility and discretionary activity participation. Additionally, we recommend the introduction of race-related variables in OD surveys to capture activity participation inequality due to race issues. We used an accessibility measure that accounts only for formal jobs and the travel time by public transport. Adopting an accessibility approach that differentiates between opportunities type and transport modes could provide different insights into the impact of accessibility on participation. Also, other accessibility measures should be tested in a causal inference framework to capture the diminishing effect on participation for the highest levels of accessibility, as suggested by Martens (2016b) and Allen and Farber (2020).

We have provided causal evidence of a relationship between accessibility and activity participation, which may help policymakers better predict and explain the impacts of inclusive transport policies based on accessibility planning. However, there is still much debate in the literature about whether this relationship is valid. Therefore, more evidence on the validity of this relationship is needed, especially in the context of the Global South. Such evidence must use identification strategies to ensure the validity of the cause-and-effect relationship between accessibility and activity participation. We have used an instrumental variable identification strategy; however, this is one of the least robust methods for inferring causality. Randomised experiments are desirable to obtain more robust results.

Our models do not address the endogeneity caused by residential self-selection. Residential selfselection refers to the tendency that people intentionally choose residential locations to meet their travel needs and preference (Mokhtarian and Cao, 2008, p.5; van Wee and Cao, 2022). The existence and the size of the effect of self-selection strongly vary according to the availability of mobility instruments (van Wee and Cao, 2022) and the housing market conditions, and it is a result of the socio-economic and demographic characteristics and attitudinal factors (Mokhtarian and Cao, 2008). Although we have inserted many socio-economic and demographic variables in our models, we could not include attitudinal factors. Also, although the instrumental variables included in the models control the bias generated by the sources of endogeneity described in section 2.1, a small share of bias may be still present due to residential self- 
Luz, G., Barboza, M. H. C., Portugal, L., Giannotti, M., van Wee, B. (2022). Does better accessibility help to reduce social exclusion? Evidence from the city of São Paulo, Brazil. Transportation Research Part A: Policy and Practice, 166, 186-217. https://doi.org/10.1016/i.tra.2022.10.005

selection. Further research must have this issue in mind and, ideally, use instruments or other research designs able to address the issue.

Although the concept of accessibility has been increasingly and widely discussed by researchers, its adoption in policies and practice is still limited. Boisjoly and El-Geneidy (2017b) found that only $55 \%$ of the 343 interviewed practitioners worldwide confirmed that they use accessibility metrics in their practice. Vecchio et al. (2020) shed light on this issue in Latin America. We may say that Sao Paulo is one of the examples of a big city with huge inequalities that do not even suggest the use of accessibility measures in its transportation planning instruments. The two latest transportation planning documents, the PITU 2025 (Plano Integrado de Transportes Urbanos, 2006), which is the last available transportation plan for the Metropolitan Region from 2006, and the Mobility Plan (2015) prepared for the city, rarely even mention the concept of accessibility, and when it does it is related to the universal accessibility of people with a mobility restriction, or it is mentioned in a broader and generic sense. Both plans did not present, compute or use accessibility metrics within their proposal. So hopefully, this paper, with a robust method to infer causal relation, may help convince practitioners of the importance of using accessibility metrics and including them in the following transportation plans to support better and more inclusive policies.

\section{Acknowledgement}

We thank two anonymous reviewers for their useful comments on our draft paper.

\section{References}

1. H. Akaike. Information Theory and an Extension of the Maximum Likelihood Principle. In B. Petrov and F. Csaki, editors, International Symposium on Information Theory, pages 267-281. 1973.

2. J. Allen and S. Farber. Planning transport for social inclusion: An accessibility-activity participation approach. Transportation Research Part D: Transport and Environment, 78:102212, 2020. doi: 10.1016/j.trd.2019.102212.

3. Arranz-López, J. A. Soria-Lara, and Á. Pueyo-Campos. Social and spatial equity effects of non-motorised accessibility to retail. Cities, 86(May 2018):71-82, mar 2019. doi: 10.1016/j.cities.2018.12.012.

4. T. Bantis and J. Haworth. Assessing transport related social exclusion using a capabilities approach to accessibility framework: A dynamic Bayesian network approach. Journal of Transport Geography, 84(January):102673, 2020. doi: 10.1016/j.jtrangeo.2020. 102673.

5. M. H. Barboza, M. S. Carneiro, C. Falavigna, G. Luz, and R. Orrico. Balancing time: Using a new accessibility measure in Rio de Janeiro. Journal of Transport Geography, 90:102924, jan 2021. doi: 10.1016/j.jtrangeo.2020.102924.

6. J. Bastiaanssen, D. Johnson, and K. Lucas. Does better job accessibility help people gain employment? The role of public transport in Great Britain. Urban Studies, page 004209802110126, may 2021. doi: 10.1177/00420980211012635.

7. C. Bhat, K. Goulias, R. Pendyala, R. Paleti, R. Sidharthan, L. Schmitt, and H.-H. Hu. A household-level activity pattern generation model with an application for Southern California. Transportation, 40(5):1063-1086, September 2013. doi: 10.1007/s11116-0139452-y. 
8. C. Biderman. São Paulo's urban transport infrastructure. Urban age newspaper essay. Technical report, 2008.

9. Bittencourt, T. A.; Giannotti, M. The unequal impacts of time, cost and transfer accessibility on cities, classes and races. Cities., v.116, p.103257, 2021. DOI: https://doi.org/10.1016/j.cities.2021.103257

10. J. Black and M. Conroy. Accessibility Measures and the Social Evaluation of Urban Structure. Environment and Planning A: Economy and Space, 9(9):1013-1031, 1977. doi: 10.1068/a091013.

11. J. P. Bocarejo S. and D. R. Oviedo H. Transport accessibility and social inequities: a tool for identification of mobility needs and evaluation of transport investments. Journal of Transport Geography, 24:142-154, sep 2012. doi: 10.1016/j.jtrangeo.2011.12.004.

12. G. Boisjoly and A. M. El-Geneidy. How to get there? A critical assessment of accessibility objectives and indicators in metropolitan transportation plans. Transport Policy, 55(February):38-50, 2017a. doi: 10.1016/j.tranpol.2016.12.011.

13. G. Boisjoly and A. M. El-Geneidy. The insider: A planners' perspective on accessibility. Journal of Transport Geography, 64:33-43, oct 2017b. doi: 10.1016/j.jtrangeo.2017.08.006.

14. G. Boisjoly, A. I. Moreno-Monroy, and A. El-Geneidy. Informality and accessibility to jobs by public transit: Evidence from the São Paulo Metropolitan Region. Journal of Transport Geography, 64:89-96, oct 2017. doi: 10.1016/j.jtrangeo.2017.08.005.

15. G. Boisjoly, B. Serra, G. T. Oliveira, and A. El-Geneidy. Accessibility measurements in São Paulo, Rio de Janeiro, Curitiba and Recife, Brazil. Journal of Transport Geography, 82, 2020. doi: 10.1016/j.jtrangeo.2019.102551.

16. K. A. Bollen and J. Pearl. Eight Myths About Causality and Structural Equation Models. pages 301-328. 2013. doi: 10.1007/978-94007-6094-3_15.

17. T. Burchardt, J. Le Grand, and D. Piachaud. Social exclusion in Britain 1991-1995. Social Policy and Administration, 33(3): 227-244, 1999. doi: 10.1111/1467-9515.00148.

18. F. Calvo, L. Eboli, C. Forciniti, and G. Mazzulla. Factors influencing trip generation on metro system in Madrid (Spain). Transportation Research Part D: Transport and Environment, 67:156-172, 2019. doi: 10.1016/j.trd.2018.11.021.

19. Cameron and P. Trivedi. Regression-based tests for overdispersion in the poisson model. Journal of Econometrics, 46(3):347-364, 1990.

20. C. Cameron and P. K. Trivedi. Regression Analysis of Count Data. Cambridge University Press, Cambridge, 1998. doi: 10.1017/CBO9780511814365.

21. C. Cameron and P. K. Trivedi. Microeconometrics Using Stata: Revised Edition. Stata Press, 2010.

22. G. Capano and M. Howlett. Causal logics and mechanisms in policy design: How and why adopting a mechanistic perspective can improve policy design. Public Policy and Administration, 36(2):141-162, 2021. doi: 10.1177/0952076719827068.

23. L. Cheng, X. Chen, S. Yang, J. Wu, and M. Yang. Structural equation models to analyze activity participation, trip generation, and mode choice of low-income commuters. Transportation Letters, 11(6):341-349, 2019. doi: 10.1080/19427867.2017.1364460.

24. Companhia do Metropolitano de São Paulo - Metrô. Relatório Síntese - Pesquisa Origem Destino 2017. Technical report, 2019.

25. Cordera, P. Coppola, L. Dell'Olio, and Á. Ibeas. Is accessibility relevant in trip generation? Modelling the interaction between trip generation and accessibility taking into account spatial effects. Transportation, 44(6):1577-1603, 2017. doi: 10.1007/ s11116-0169715-5.

26. Cunningham. Causal Inference: The Mixtape. Yale University Press, 2021.

27. Curl, J. D. Nelson, and J. Anable. Does accessibility planning address what matters? A review of current practice and practitioner perspectives. Research in Transportation Business and Management, 2:3-11, 2011. doi: 10.1016/j.rtbm.2011.07.001.

28. A. Delbosc and G. Currie. Exploring the relative influences of transport disadvantage and social exclusion on well-being. Transport Policy, 18(4):555-562, aug 2011. doi: 10.1016/j.tranpol.2011.01.011.

29. D. Denmark. The Outsiders: Planning and Transport Disadvantage. Journal of Planning Education and Research, 17:231 - 245, 1998.

30. Y. Ding, H. Lu, and X. Sun. Impact of improved accessibility on shopping activity: Person-based measure. Journal of Urban Planning and Development, 142(3), 2016. doi: 10.1061/(ASCE)UP.1943-5444.0000325.

31. J. D. Downes and D. Morrell. Variation of travel time budgets and trip rates in reading. Transportation Research Part A: General, 15:47-53, 1981.

32. G. Duranton and M. A. Turner. The Fundamental Law of Road Congestion: Evidence from US Cities. American Economic Review, 101(6):2616-2652, oct 2011. doi: 10.1257/aer.101.6.2616.

33. A. Engels and G. J. Liu. Social exclusion, location and transport disadvantage amongst non-driving seniors in a Melbourne municipality, Australia. Journal of Transport Geography, 19(4):984-996, jul 2011. doi: 10.1016/j.jtrangeo.2011.03.007.

34. R. Ewing, M. B. DeAnna, and S. C. Li. Land use impacts on trip generation rates. Transportation Research Record, (1518):1-6, 1996. doi: 10.3141/1518-01.

35. J. Farrington and C. Farrington. Rural accessibility, social inclusion and social justice: towards conceptualisation. Journal of Transport Geography, 13(1):1-12, mar 2005. doi: 10.1016/j.jtrangeo.2004.10.002.

36. H. Farrington. The new narrative of accessibility: its potential contribution to discourses in (transport) geography. Journal of Transport Geography, 15(5):319-330, sep 2007. doi: 10.1016/j.jtrangeo.2006.11.007.

37. Fransen, S. Farber, G. Deruyter, and P. De Maeyer. A spatio-temporal accessibility measure for modelling activity participation in discretionary activities. Travel Behaviour and Society, 10(September):10-20, 2018. doi: 10.1016/j.tbs.2017.09.002.

38. Fundação Sistema Estadual de Análise de Dados. Índice Paulista de Vulnerabilidade Social. Technical report, 2013.

39. K. Geurs and B. van Wee. Accessibility evaluation of land-use and transport strategies: Review and research directions. Journal of Transport Geography, 12(2):127-140, 2004. doi: 10.1016/j.jtrangeo.2003.10.005.

40. Giannotti, J. Barros, D. B. Tomasiello, D. Smith, B. Pizzol, B. M. Santos, C. Zhong, Y. Shen, E. Marques, and M. Batty. Inequalities in transit accessibility: Contributions from a comparative study between Global South and North metropolitan regions. Cities, 109(February 2020):103016, 2021. doi: 10.1016/j.cities.2020.103016.

41. T. F. Golob. A simultaneous model of household activity participation and trip chain generation. Transportation Research Part B: Methodological, 34(5):355-376, 2000. doi: 10.1016/S0191-2615(99)00028-4.

42. A. Griffith. Spatial Autocorrelation and Spatial Filtering. Advances in Spatial Science. Springer Berlin Heidelberg, Berlin, Heidelberg, 2003. doi: 10.1007/978-3-540-24806-4. 
43. A. Haddad and A. M. B. Barufi. From rivers to roads: Spatial mismatch and inequality of opportunity in urban labor markets of megacity. Habitat International, 68:3-14, oct 2017. doi: 10.1016/j.habitatint.2017.03.016.

44. Hananel and J. Berechman. Justice and transportation decision-making: The capabilities approach. Transport Policy, 49:78-85, 2016. doi: 10.1016/j.tranpol.2016.04.005.

45. Handy. Regional versus local accessibility. Transportation Research Record, 1400(234):58-66, 1993.

46. S. Handy and D. Niemeier. Measuring Accessibility: An Exploration of Issues and Alternatives. Environment and Planning A: Economy and Space, 29(7):1175-1194, jul 1997. doi: 10.1068/a291175.

47. S. L. Handy. Understanding the Link Between Urban Form and Nonwork Travel Behavior. Journal of Planning Education and Research, 15(3):183-198, apr 1996. doi: 10.1177/0739456X9601500303.

48. W. G. Hansen. How Accessibility Shapes Land Use. Journal of the American Planning Association, 25(2):73-76, 1959. doi:

49. $10.1080 / 01944365908978307$.

50. S. Hanson and M. Schwab. Accessibility and intraurban travel. Environment \& Planning A, 19(6):735-748, 1987. doi: 10.1068/ a190735.

51. J. Hine. Transport disadvantage and social exclusion in urban Scotland. Built Environment, 30(2):161-171, 2004. doi: 10.2148/ benv.30.2.161.54315.

52. J. Hong and P. V. Thakuriah. Relationship between motorized travel and time spent online for nonwork purposes: An examination of location impact. International Journal of Sustainable Transportation, 10(7):617-626, 2016. doi: 10.1080/15568318.2015.1079752.

53. Instituto Brasileirode Geografia e Estatística - IBGE. Sinopse do Censo Demográfico 2010. Instituto Brasileiro de Geografia e Estatística - IBGE, Rio de Janeiro, 2011.

54. Jaramillo, C. Lizárraga, and A. L. Grindlay. Spatial disparity in transport social needs and public transport provision in Santiago de Cali (Colombia). Journal of Transport Geography, 24:340-357, sep 2012. doi: 10.1016/j.jtrangeo.2012.04.014.

55. J. F. Jeekel and C. J. C. M. Martens. Equity in transport: Learning from the policy domains of housing, health care and education. European Transport Research Review, 9(4):53, dec 2017. doi: 10.1007/s12544-017-0269-1.

56. J. Jin and K. Paulsen. Does accessibility matter? Understanding the effect of job accessibility on labour market outcomes. Urban Studies, 55(1):91-115, jan 2018. doi: 10.1177/0042098016684099.

57. Kamruzzaman and J. Hine. Analysis of rural activity spaces and transport disadvantage using a multi-method approach. Transport Policy, 19(1):105-120, jan 2012. doi: 10.1016/j.tranpol.2011.09.007.

58. Kamruzzaman, T. Yigitcanlar, J. Yang, and M. A. Mohamed. Measures of transport-related social exclusion: A critical review of the literature. Sustainability (Switzerland), 8(7):6-11, 2016. doi: 10.3390/su8070696.

59. S. Kenyon, G. Lyons, and J. Rafferty. Transport and social exclusion: investigating the possibility of promoting inclusion through virtual mobility. Journal of Transport Geography, 10(3):207-219, sep 2002. doi: 10.1016/S0966-6923(02)00012-1.

60. R. Kitamura, P. L. Mokhtarian, and L. Laidet. A micro-analysis of land use and travel in five neighborhoods in the San Francisco Bay Area. Transportation, 24:125-158, 1997. doi: https://doi.org/10.1023/A:1017959825565.

61. R. Kitamura, T. Akiyama, T. Yamamoto, and T. F. Golob. Accessibility in a metropolis: Toward a better understanding of land use and travel. Transportation Research Record, (1780):64-75, 2001. doi: 10.3141/1780-08.

62. J. G. Koenig. Indicators of urban accessibility: Theory and application. Transportation, 9(2):145-172, jun 1980. doi: 10.1007/ BF00167128.

63. Krasić and L. Novačko. The impact of public transport network accessibility on trip generation model. Promet Trafficamp;Transportation, 27(2):165-172, Apr. 2015. doi: 10.7307/ptt.v27i2.1591.

64. L. Kröger, F. Heinitz, and C. Winkler. Operationalizing a spatial differentiation of trip generation rates using proxy indicators of accessibility. Travel Behaviour and Society, 11:156-173, 2018. doi: 10.1016/j.tbs.2017.07.002.

65. M.-p. Kwan. Accessibility : A Comparative Anal ysis Using a Point-based Framework. GeoGraphical Analysis, 30(9512451): 191-216, 1998.

66. U. Landau, J. N. Prashker, and M. Hirsh. The effect of temporal constraints on household travel behavior. Environment and Planning A, 13(4):435-448, 1981. doi: 10.1068/a130435

67. U. Landau, J. N. Prashker, and B. Alpern. Evaluation of activity constrained choice sets to shopping destination choice modelling. Transportation Research Part A: General, 16(3):199-207, 1982. doi: 10.1016/0191-2607(82)90021-8.

68. S. Lavieri, Q. Dai, and C. R. Bhat. Using virtual accessibility and physical accessibility as joint predictors of activity-travel behavior. Transportation Research Part A: Policy and Practice, 118:527-544, 2018. doi: 10.1016/j.tra.2018.08.042.

69. G. R. Leake and A. S. Huzayyin. IMportance of accessibility measures in trip production models. Transportation Planning and Technology, 6(1):9-20, 1980. doi: 10.1080/03081068008717170.

70. M.-S. Lee and K. Goulias. Accessibility indicators for transportation planning using GIS. Transportation Research Part A, 13 (December 1996):91-109, 1997.

71. LeSage and R. K. Pace. Introduction to Spatial Econometrics. Chapman and Hall/CRC, 2009.

72. Lucas. Providing transport for social inclusion within a framework for environmental justice in the UK. Transportation Research Part A: Policy and Practice, 40(10):801-809, dec 2006. doi: 10.1016/j.tra.2005.12.005.

73. K. Lucas. Making the connections between transport disadvantage and the social exclusion of low income populations in the Tshwane Region of South Africa. Journal of Transport Geography, 19(6):1320-1334, nov 2011. doi: 10.1016/j.jtrangeo.2011.02.007.

74. K. Lucas. Transport and social exclusion: Where are we now? Transport Policy, 20:105-113, mar 2012. doi: 10.1016/j.tranpol. 2012.01.013.

75. K. Lucas, B. van Wee, and K. Maat. A method to evaluate equitable accessibility: combining ethical theories and accessibility-based approaches. Transportation, 43(3):473-490, may 2016. doi: 10.1007/s11116-015-9585-2.

76. G. Luz and L. Portugal. Understanding transport-related social exclusion through the lens of capabilities approach. Transport Reviews, 0(0):1-23, 2021. doi: 10.1080/01441647.2021.2005183. 
77. L. Ma, J. L. Kent, and C. Mulley. Transport disadvantage, social exclusion, and subjective well-being: The role of the neighborhood environment-evidence from Sydney, Australia. Journal of Transport and Land Use, 11(1):31-47, 2018. doi: 10.5198/jtlu.2018. 1008.

78. K. Martens. Why Accessibility Measurement is Not Merely an Option, but an Absolute Necessity. Designing Accessibility Instruments, (July):37-51, 2016a. doi: 10.4324/9781315463612-4.

79. K. Martens. Transport Justice. Routledge, 2016b.

80. H. Masoumi. Home-based urban commute and non-commute trip generation in less-studied contexts: Evidence from cairo, istanbul, and tehran. Case Studies on Transport Policy, 2021. doi: https://doi.org/10.1016/j.cstp.2021.11.011.

81. G. Mattioli. Where Sustainable Transport and Social Exclusion Meet: Households Without Cars and Car Dependence in Great Britain. Journal of Environmental Policy and Planning, 16(3):379-400, jul 2014. doi: 10.1080/1523908X.2013.858592.

82. L. A. Merlin. Can the built environment influence nonwork activity participation? An analysis with national data. Transportation, 42(2):369-387, 2015. doi: 10.1007/s11116-014-9554-1.

83. R. M. P. Meyer, M. D. Gronstein, and C. Biderman. São Paulo Metrópole. EDUSP, 1st editio edition, 2004.

84. Miller, H. J., Tribby, C. P., Brown, B. B., Smith, K. R., Werner, C. M., Wolf, J., ... \& Oliveira, M. G. S. (2015). Public transit generates new physical activity: evidence from individual GPS and accelerometer data before and after light rail construction in a neighborhood of Salt Lake City, Utah, USA. Health \& place, 36, 8-17.

85. Mokhtarian, P. L., \& Cao, X. (2008). Examining the impacts of residential self-selection on travel behavior: A focus on methodologies. Transportation Research Part B: Methodological, 42(3), 204-228.

86. L. Mokhtarian and I. Salomon. Modeling the desire to telecommute: The importance of attitudinal factors in behavioral models. Transportation Research Part A: Policy and Practice, 31(1):35-50, 1997. doi: 10.1016/S0965-8564(96)00010-9.

87. I. Moreno-Monroy and F. R. Ramos. The impact of public transport expansions on informality: The case of the São Paulo Metropolitan Region. Research in Transportation Economics, (xxxx):100928, 2020. doi: 10.1016/j.retrec.2020.100928.

88. J. Mullahy. Instrumental-Variable Estimation of Count Data Models: Applications to Models of Cigarette Smoking Behavior. Review of Economics and Statistics, 79(4):586-593, nov 1997. doi: 10.1162/003465397557169.

89. P. Næss. Accessibility, activity participation and location of activities: Exploring the links between residential location and travel behaviour. Urban Studies, 43(3):627-652, 2006. doi: 10.1080/00420980500534677.

90. T. Neutens. Accessibility, equity and health care: Review and research directions for transport geographers. Journal of Transport Geography, 43:14-27, 2015. doi: 10.1016/j.jtrangeo.2014.12.006.

91. T. Neutens, T. Schwanen, F. Witlox, and P. de Maeyer. Equity of urban service delivery: A comparison of different accessibility measures. Environment and Planning A, 42(7):1613-1635, 2010. doi: 10.1068/a4230.

92. Páez, R. G. Mercado, S. Farber, C. Morency, and M. Roorda. Relative accessibility deprivation indicators for urban settings: Definitions and application to food deserts in montreal. Urban Studies, 47(7):1415-1438, 2010. doi: 10.1177/0042098009353626.

93. R. H. Pereira, T. Schwanen, and D. Banister. Distributive justice and equity in transportation. Transport Reviews, 37(2):170-191, mar 2017. doi: 10.1080/01441647.2016.1257660.

94. R. H. M. Pereira, C. K. V. Braga, B. Serra, and V. Nadalin. Desigualdades socioespaciais de acesso a oportunidades nas cidades brasileiras, 2019. Texto para Discussão IPEA, 2535, 2019.

95. Pizzol, B., Giannotti, M., \& Tomasiello, D. B. (2021). Qualifying accessibility to education to investigate spatial equity. Journal of Transport Geography, 96, 103199 doi: 10.1016/j.jtrangeo.2021.103199

96. Prefeitura De São Paulo. Plano de Mobilidade Urbana do Município de São Paulo 2015, 2015.

97. J. Preston and F. Rajé. Accessibility, mobility and transport-related social exclusion. Journal of Transport Geography, 15(3): 151160, may 2007. doi: 10.1016/j.jtrangeo.2006.05.002.

98. P. Pucci, G. Vecchio, L. Bocchimuzzi, and G. Lanza. Inequalities in job-related accessibility: Testing an evaluative approach and its policy relevance in Buenos Aires. Applied Geography, 107:1-11, jun 2019. doi: 10.1016/j.apgeog.2019.04.002.

99. C. L. Purvis, M. Iglesias, and V. A. Eisen. Incorporating Work Trip Accessibility in Nonwork Trip Generation Models in San Francisco Bay Area. Transportation Research Record: Journal of the Transportation Research Board, 1556(1):37-45, jan 1996. doi: 10.1177/0361198196155600106.

100. V. D. Pyrialakou, K. Gkritza, and J. D. Fricker. Accessibility, mobility, and realized travel behavior: Assessing transport disadvantage from a policy perspective. Journal of Transport Geography, 51:252-269, feb 2016. doi: 10.1016/j.jtrangeo.2016.02.001. P. Roback and J. Legler. Beyond Multiple Linear Regression. Chapman and Hall/CRC, jan 2021. doi: 10.1201/9780429066665.

101. R. V. Robinson and R. W. Vickerman. The demand for shopping travel: A theoretical and empirical study. Applied Economics, 8 (4):267-281, 1976. doi: 10.1080/00036847600000023.

102. T. Schwanen, D. Ettema, and H. Timmermans. If you pick up the children, I'll do the groceries: Spatial differences in between partner interactions in out-of-home household activities. Environment and Planning A, 39(11):2754-2773, 2007. doi: 10.1068/ a38491.

103. Secretaria Dos Transportes Metropolitanos PITU 2025 - Plano Integrado de Transportes Urbanos - Parte D: Inovando nas estratégias de transportes. 2006

104. A. Sen. Poverty and Famines. Oxford University Press, jan 1983. doi: 10.1093/0198284632.001.0001.

105. S. E. Seo, N. Ohmori, and N. Harata. Effects of household structure and accessibility on travel. Transportation, 40(4):847-865, 2013. doi: 10.1007/s11116-013-9468-3.

106. I. Shergold and G. Parkhurst. Transport-related social exclusion amongst older people in rural Southwest England and Wales Journal of Rural Studies, 28(4):412-421, oct 2012. doi: 10.1016/j.jrurstud.2012.01.010.

107. D. Slovic, D. B. Tomasiello, M. Giannotti, M. d. F. Andrade, and A. C. Nardocci. The long road to achieving equity: Job accessibility restrictions and overlapping inequalities in the city of São Paulo. Journal of Transport Geography, 78(November 2018):181-193, 2019. doi: 10.1016/j.jtrangeo.2019.06.003.

108. Social Exclusion Unit. Making the Connections: Final Report on Transport and Social Exclusion. Technical report, Social Exclusion Unit - Office of the Deputy Prime Minister, London, 2003.

109. P. F. Steinberg. Causal Assessment in Small-N Policy Studies. Policy Studies Journal, 35(2):181-204, may 2007. doi: 10.1111/j. 15410072.2007.00215.x. 
110. I. C. Thill and M. Kim. Trip making, induced travel demand, and accessibility. Journal of Geographical Systems, 7(2):229-248, 2005. doi: 10.1007/s10109-005-0158-3.

111. G. Tian and R. Ewing. A walk trip generation model for Portland, OR. Transportation Research Part D: Transport and Environment, 52:340-353, 2017. doi: 10.1016/j.trd.2017.03.017.

112. United Nations. Leaving No One Behind - The Imperative of Inclusive Development. Technical report, United Nations, 2016.

113. S. Ureta. To move or not to move? Social exclusion, accessibility and daily mobility among the low-income population in Santiago, Chile. Mobilities, 3(2):269-289, jul 2008. doi: 10.1080/17450100802095338.

114. S. van der Veen, J. A. Annema, K. Martens, B. van Arem, and G. H. d. A. Correia. Operationalizing an indicator of sufficient accessibility - a case study for the city of Rotterdam. Case Studies on Transport Policy, 8(4):1360-1370, dec 2020. doi: 10.1016/j.cstp.2020.09.007.

115. van Wee, B., \& Cao, X. J. (2022). Residential self-selection in the relationship between the built environment and travel behavior: A literature review and research agenda. Journal: Advances in Transport Policy and Planning Urban Transport and Land Use Planning: A Synthesis of Global Knowledge, 75-94.

116. B. van Wee and K. Geurs. Discussing equity and social exclusion in accessibility evaluations. European Journal of Transport and Infrastructure Research, 11(4):350-367, sep 2011.

117. G. Vecchio and K. Martens. Accessibility and the Capabilities Approach: a review of the literature and proposal for conceptual advancements. Transport Reviews, 41(6):833-854, nov 2021. doi: 10.1080/01441647.2021.1931551.

118. G. Vecchio, I. Tiznado-Aitken \& R. Hurtubia (2020) Transport and equity in Latin America: a critical review of socially oriented accessibility assessments, Transport Reviews, 40:3, 354-381, DOI: 10.1080/01441647.2020.1711828

119. R. W. Vickerman. Accessibility, Attraction, and Potential: A Review of Some Concepts and Their Use in Determining Mobility. Environment and Planning A: Economy and Space, 6(6):675-691, 1974. doi: 10.1068/a060675.

120. M. Wachs and T. G. Kumagai. Physical accessibility as a social indicator. Socio-Economic Planning Sciences, 7(5):437-456, 1973. doi: 10.1016/0038-0121(73)90041-4.

121. A. Walks. Driving the poor into debt? Automobile loans, transport disadvantage, and automobile dependence. Transport Policy, 65:137-149, jul 2018. doi: 10.1016/j.tranpol.2017.01.001.

122. C. Wang and X. Cao. Impacts of the built environment on activity-travel behavior: Are there differences between public and private housing residents in Hong Kong? Transportation Research Part A: Policy and Practice, 103(C):25-35, 2017. doi: 10.1016/j.tra.2017.05.018.

123. M. J. Wermuth. Hierarchical Effects of Personal, Household, and Residential Location Characteristics on Individual Activity Demand. Environment and Planning A: Economy and Space, 14(9):1251-1264, sep 1982. doi: 10.1068/a141251.

124. P. A. Williams. The influence of residential accessibility on household trip-making. Socio-Economic Planning Sciences, 23(6): 373385, 1989. doi: 10.1016/0038-0121(89)90005-0.

125. A. G. Windmeijer and J. M. C. S. Silva. Endogeneity in count data models: An application to demand for health care. Journal of Applied Econometrics, 12(3):281-294, 1997.

126. J. Wooldridge. Introductory Econometrics: A Modern Approach. Nelson Education, Toronto, Canada, 2015.

127. D. Wu, E. Sall, and S. Newhouse. Trip rates and accessibility. Transportation Research Record, (2303):81-88, 2012. doi: 10.3141/ 2303-09.

128. R. Xiao, G. Wang, and M. Wang. Transportation Disadvantage and Neighborhood Sociodemographics: A Composite Indicator Approach to Examining Social Inequalities. Social Indicators Research, 137(1):29-43, may 2018. doi: 10.1007/s11205-017-1616-2.

129. Zhang. Exploring the relationship between urban form and nonwork travel through time use analysis. Landscape and Urban Planning, 73(2):244-261, 2005 doi: https://doi.org/10.1016/j.landurbplan.2004.11.008. Research on the Built and Virtual Environments.

130. Q. Zhang, K. J. Clifton, R. Moeckel, and J. Orrego-Oñate. Household Trip Generation and the Built Environment: Does More Density Mean More Trips? Transportation Research Record, 2673(5):596-606, 2019. doi: 10.1177/0361198119841854.

131. Zhang, Y., Farber, S., \& Young, M. (2021). Eliminating barriers to nighttime activity participation: the case of on-demand transit in Belleville, Canada. Transportation, 1-24. 
Luz, G., Barboza, M. H. C., Portugal, L., Giannotti, M., van Wee, B. (2022). Does better accessibility help to reduce social exclusion? Evidence from the city of São Paulo, Brazil. Transportation Research Part A: Policy and Practice, 166, 186-217. https://doi.org/10.1016/i.tra.2022.10.005

\section{Appendix A: Overview of the studies and empirical evidence about the relationship between accessibility and activity participation and trip making}

Table A -Overview of the studies and empirical evidence about the relationship between accessibility and activity participation and trip making

\begin{tabular}{|c|c|c|c|c|c|c|c|}
\hline Author & Study Area & Accessibility Measure & Method & Study focus & Trip / Activity Purpose & Transport Mode & Findings \\
\hline $\begin{array}{l}\text { Vickerman } \\
\text { (1974) }\end{array}$ & $\begin{array}{l}\text { Oxford, } \\
\text { Kingdom }\end{array}$ & Place-based (Gravity-type) & $\begin{array}{l}\text { Multivariate linear } \\
\text { regression }\end{array}$ & Trip making & hopping; Leisure & $\begin{array}{l}\text { All travel modes, Auto, } \\
\text { Public Transit and } \\
\text { Walk }\end{array}$ & $\begin{array}{l}\text { Positive effect. The cost component of accessibility measure positively } \\
\text { impacts shopping trips, while the attraction component has a dominant } \\
\text { influence on leisure trips. }\end{array}$ \\
\hline $\begin{array}{l}\text { Robinson and } \\
\text { Vickerman } \\
\text { (1976) }\end{array}$ & $\begin{array}{l}\text { Sussex, } \\
\text { Kingdom }\end{array}$ & Place-based (Gravity-type) & $\begin{array}{l}\text { Multivariate linear } \\
\text { regression }\end{array}$ & Trip making & Shopping & $\begin{array}{l}\text { Auto and Public } \\
\text { Transit }\end{array}$ & $\begin{array}{l}\text { Positive effect. The availability of shopping locations in a given area and } \\
\text { their transport characteristics positively influence shopping activity. }\end{array}$ \\
\hline Koenig (1980) & $\begin{array}{l}\text { Lemans, Marseilles, } \\
\text { Rouen, Nice, } \\
\text { Grenoble - France }\end{array}$ & Utility-based & $\begin{array}{l}\text { Basic descriptive } \\
\text { statistics }\end{array}$ & Trip making & Work & $\begin{array}{l}\text { Auto and Public } \\
\text { Transit }\end{array}$ & Positive effect. Accessibility is a powerful determinant of trip rate. \\
\hline $\begin{array}{l}\text { Leake and } \\
\text { Huzayyin (1980) }\end{array}$ & $\begin{array}{l}\text { Middlesbrough, } \\
\text { United Kingdom }\end{array}$ & $\begin{array}{l}\text { Place-based (Minimum distance; } \\
\text { Minimum time) and } \\
\text { Infrastructure-based (Headway; } \\
\text { Transport Network structure) }\end{array}$ & $\begin{array}{l}\text { Multivariate linear } \\
\text { regression }\end{array}$ & Trip making & $\begin{array}{l}\text { Work; Education; Others; } \\
\text { General }\end{array}$ & $\begin{array}{l}\text { All travel modes, Auto } \\
\text { and Public Transit }\end{array}$ & $\begin{array}{l}\text { Positive effect. The most affected trip types were public transport trips } \\
\text { followed by "all mode" trips. The more negligible impact was for trips by } \\
\text { private transport. The most significant effect by trip purpose was on home- } \\
\text { based other trips, regardless of travel mode. }\end{array}$ \\
\hline $\begin{array}{l}\text { Landau et al. } \\
\text { (1981) }\end{array}$ & Tel-Aviv, Israel & $\begin{array}{l}\text { Spatial-temporal (Possible } \\
\text { activity duration) and Place- } \\
\text { based (Container-type) }\end{array}$ & $\begin{array}{l}\text { Linear probability } \\
\text { model }\end{array}$ & Trip making & Maintenance; Leisure & $\begin{array}{l}\text { Auto and Public } \\
\text { Transit }\end{array}$ & $\begin{array}{l}\text { Mixed effect. Time constraints were significant in the leisure trip models } \\
\text { and not in the maintenance trips models. The number of employees in } \\
\text { commerce and services in residential areas positively influences the } \\
\text { number of maintenance trips but negatively influences leisure trip making. }\end{array}$ \\
\hline $\begin{array}{l}\text { Downes and } \\
\text { Morrel (1981) }\end{array}$ & $\begin{array}{l}\text { Reading, United } \\
\text { Kingdom }\end{array}$ & Place-based (Distance to CBD) & $\begin{array}{l}\text { Descriptive } \\
\text { statistics }\end{array}$ & Trip making & General & $\begin{array}{l}\text { Auto, Public Transit, } \\
\text { Bicycle and Walk }\end{array}$ & $\begin{array}{l}\text { No significant effect. Household locations do not affect the aggregate trip } \\
\text { frequency by all modes. }\end{array}$ \\
\hline Wermuth (1982) & $\begin{array}{l}\text { Rhine-Neckar } \\
\text { (Germany) and } \\
\text { Salzburg (Austria) }\end{array}$ & $\begin{array}{l}\text { Place-based } \\
\text { characteristics) }\end{array}$ & Nested ANOVA & $\begin{array}{l}\text { Activity } \\
\text { participation }\end{array}$ & $\begin{array}{l}\text { Work; } \quad \text { Education; } \\
\text { Shopping; Leisure; Others }\end{array}$ & All travel modes & $\begin{array}{l}\text { No significant effect. The accessibility to central facilities and the } \\
\text { characteristics of the residential neighbourhood is negligible. }\end{array}$ \\
\hline $\begin{array}{l}\text { Hanson and } \\
\text { Schwab (1987) }\end{array}$ & Uppsala, Sweden & Place-based (Gravity-type) & $\begin{array}{l}\text { Multivariate linear } \\
\text { regression }\end{array}$ & Trip $\mathrm{m}$ & $\begin{array}{l}\text { Discretionary (Non-work; } \\
\text { Shopping; Social) }\end{array}$ & Auto, Walk and Bicycle & $\begin{array}{l}\text { ionship between accessibility and the number of } \\
\text { atistically significant only for men. The correlation } \\
\text { y expressive. }\end{array}$ \\
\hline Williams (1989) & Hamilton, Canada & Place-based (Gravity-type) & $\begin{array}{l}\text { Pearson correlation } \\
\text { coefficient and } \\
\text { ANOVA }\end{array}$ & $\begin{array}{l}\text { Trip making and } \\
\text { Activity } \\
\text { participation }\end{array}$ & General & Auto & $\begin{array}{l}\text { Negative effect. The activity participation reduces as accessibility increases. } \\
\text { No association was found between the number of trips made and the } \\
\text { accessibility conditions. }\end{array}$ \\
\hline Handy (1993) & $\begin{array}{l}\text { San Franciso Bay } \\
\text { Area, United States }\end{array}$ & Place-based (Gravity-type) & $\begin{array}{l}\text { Pearson correlation } \\
\text { coefficient }\end{array}$ & Trip making & Shopping & Auto & $\begin{array}{l}\text { No significant effect. The relationship between regional accessibility and } \\
\text { shopping trips was practically non-existent, as was the relationship } \\
\text { between local accessibility and shopping trips. }\end{array}$ \\
\hline $\begin{array}{l}\text { Ewing et } \\
\text { (1996) }\end{array}$ & $\begin{array}{l}\text { Palm Beach and } \\
\text { Dade } \quad \text { counties, } \\
\text { Florida, United }\end{array}$ & Place-based (Gravity-type) & ANOVA & Trip & $\begin{array}{l}\text { Mandatory (Work) and } \\
\text { Discretionary (Shopping; } \\
\text { Social; Recreation; Others) }\end{array}$ & Auto, Wa & $\begin{array}{l}\text { No significant effect. Accessibility seems to have negligible effects on home- } \\
\text { based trip generation. }\end{array}$ \\
\hline
\end{tabular}


Luz, G., Barboza, M. H. C., Portugal, L., Giannotti, M., van Wee, B. (2022). Does better accessibility help to reduce social exclusion? Evidence from the city of São Paulo, Brazil. Transportation Research Part A: Policy and Practice, 166, 186-217. https://doi.org/10.1016/i.tra.2022.10.005

\begin{tabular}{|c|c|c|c|c|c|c|c|}
\hline Author & Study Area & Accessibility Measure & Method & Study focus & Trip / Activity Purpose & Transport Mode & Findings \\
\hline Handy (1996) & $\begin{array}{l}\text { San Franciso Bay } \\
\text { Area, United States }\end{array}$ & $\begin{array}{l}\text { Place-based } \\
\text { Opportunities; Weighted time; } \\
\text { Minimum time) }\end{array}$ & $\begin{array}{l}\text { Descriptive data } \\
\text { analysis and ANOVA }\end{array}$ & Trip making & $\begin{array}{l}\text { Discretionary } \\
\text { Supermarket; Having Meal) }\end{array}$ & Auto and Walk & $\begin{array}{l}\text { Positive effect. Greater accessibility, both in terms of short distances and a } \\
\text { greater variety of potential destinations, is associated with higher trip } \\
\text { frequencies to convenience stores and regional trips to shopping centres. }\end{array}$ \\
\hline $\begin{array}{l}\text { Purvis et al. } \\
\text { (1996) }\end{array}$ & $\begin{array}{l}\text { San Franciso Bay } \\
\text { Area, United States }\end{array}$ & Place-based (Minimum time) & $\begin{array}{l}\text { Multivariate linear } \\
\text { regression }\end{array}$ & Trip making & Shopping; Leisure & Auto, Walk and Bicycle & $\begin{array}{l}\text { Positive effect. There is an inverse relationship between work trip duration } \\
\text { and trip frequency for reasons other than work. }\end{array}$ \\
\hline $\begin{array}{l}\text { Lee e Goulias } \\
\text { (1997) }\end{array}$ & $\begin{array}{l}\text { Centre County, } \\
\text { Pennsylvania, } \\
\text { United States }\end{array}$ & $\begin{array}{l}\text { Place-based (Minimum distance; } \\
\text { Minimum time; Distance sum; } \\
\text { Weighted distance; Gravity- } \\
\text { type) }\end{array}$ & Logit & Trip making & Shopping & Auto & $\begin{array}{l}\text { Positive effect. The shortest path (minimum distance) measure and the } \\
\text { gravity-type with a Gaussian deterrence function accessibility measure are } \\
\text { the ones that best explain travel behaviour. }\end{array}$ \\
\hline $\begin{array}{l}\text { Kitamura et al. } \\
\text { (1997) }\end{array}$ & $\begin{array}{l}\text { San Franciso Bay } \\
\text { Area, United States }\end{array}$ & $\begin{array}{l}\text { Place-based (Minimum distance } \\
\text { to transport; Minimum distance; } \\
\text { Household Density) }\end{array}$ & $\begin{array}{l}\text { Multivariate linear } \\
\text { regression }\end{array}$ & Trip making & General & $\begin{array}{l}\text { Public transit, Walk } \\
\text { and Bicycle }\end{array}$ & $\begin{array}{l}\text { Weak effect. The number of public transport trips increases with better } \\
\text { accessibility to railway stations and is associated with residential density. } \\
\text { The presence of sidewalks is positively associated with the number of non- } \\
\text { motorised trips. Attitudes are more strongly associated with travel than are } \\
\text { land use characteristics }\end{array}$ \\
\hline Golob (2000) & $\begin{array}{l}\text { Portland, Oregon, } \\
\text { United States }\end{array}$ & $\begin{array}{l}\text { Place-based (Cumulative } \\
\text { Opportunities) and Utility-based }\end{array}$ & $\begin{array}{l}\text { Structural Equation } \\
\text { Modelling }\end{array}$ & $\begin{array}{l}\text { Activity } \\
\text { participation }\end{array}$ & $\begin{array}{l}\text { Work, Maintenance and } \\
\text { Discretionary (Leisure) }\end{array}$ & All travel modes & $\begin{array}{l}\text { Positive effect. Accessibility levels are positively related to participation in } \\
\text { out-of-home non-work activities, simple home-based trip chains for non- } \\
\text { work purposes, and negatively related to work travel time. }\end{array}$ \\
\hline $\begin{array}{l}\text { Kitamura et al. } \\
\text { (2001) }\end{array}$ & $\begin{array}{l}\text { Kyoto-Osaka-Kobe } \\
\text { Metropolitan Area, } \\
\text { Japan, and } \\
\text { Southern California, } \\
\text { United States }\end{array}$ & $\begin{array}{l}\text { Place-based (Gravity-type) and } \\
\text { Spatio-temporal (Number of } \\
\text { activities in the Space-time } \\
\text { Prism; Volume of Space-time } \\
\text { Prism) }\end{array}$ & $\begin{array}{l}\text { Pearson correlation } \\
\text { coefficient and } \\
\text { structural equation } \\
\text { modelling }\end{array}$ & $\begin{array}{l}\text { Trip making and } \\
\text { Activity } \\
\text { participation }\end{array}$ & Shopping and Leisure & $\begin{array}{l}\text { Auto and Public } \\
\text { Transit }\end{array}$ & $\begin{array}{l}\text { Mixed effect. The size of the space-time prism, not the number of } \\
\text { opportunities it contains, is the critical determinant of activity participation. } \\
\text { Time availability is more influential than the opportunities distribution in } \\
\text { activity participation and trip making (Japan). }\end{array}$ \\
\hline Thill e Kim (2005) & $\begin{array}{l}\text { Minneapolis-St. } \\
\text { Paul, Minnesota, } \\
\text { United States }\end{array}$ & $\begin{array}{l}\text { Place-based (Gravity-type; } \\
\text { Cumulative Opportunities) }\end{array}$ & Poisson Regression & Trip making & $\begin{array}{l}\text { Work; Shopping; Education } \\
\text { and Others }\end{array}$ & Auto & $\begin{array}{l}\text { Mixed effect. Half of the statistically significant accessibility variables } \\
\text { revealed a positive relationship with the trip making. The other half } \\
\text { indicated a negative relationship. The combined effect of significant } \\
\text { accessibility measures on travel demand is complex and non-linear. }\end{array}$ \\
\hline Zhang (2005) & $\begin{array}{l}\text { Boston, United } \\
\text { States }\end{array}$ & $\begin{array}{l}\text { Place-based } \\
\text { (Gravity-type) }\end{array}$ & Logit Regression & $\begin{array}{l}\text { Activity } \\
\text { Participation }\end{array}$ & $\begin{array}{l}\text { Non-work (school, } \\
\text { shopping, social, personal, } \\
\text { pick up/drop off and other) }\end{array}$ & $\begin{array}{l}\text { Auto and Public } \\
\text { Transport }\end{array}$ & $\begin{array}{l}\text { Mixed effect. Accessibility was positive, statistically significant to } \\
\text { activity-travel frequency for school and social activities. Increase in } \\
\text { accessibility was associated with lower odds of making additional } \\
\text { shopping trips. }\end{array}$ \\
\hline Næss (2006) & $\begin{array}{l}\text { Copenhagen } \\
\text { Metropolitan } \\
\text { Region, Denmark }\end{array}$ & Place-based (Distance to CBD) & $\begin{array}{l}\text { Interviews and } \\
\text { multivariate linear } \\
\text { regression }\end{array}$ & $\begin{array}{l}\text { Trip making and } \\
\text { Activity } \\
\text { participation }\end{array}$ & $\begin{array}{l}\text { Leisure; Maintenance; } \\
\text { Visiting friends and Work }\end{array}$ & $\begin{array}{l}\text { Auto, Public Transit, } \\
\text { Walk and Bicycle }\end{array}$ & $\begin{array}{l}\text { Mixed effect. The results indicate that respondents from the more } \\
\text { peripheral residential area tend to make } 1.5 \text { more daily trips than their } \\
\text { peers living in the area closer to the Copenhagen CBD. At the same time, } \\
\text { better accessibility is associated with more activity participation. }\end{array}$ \\
\hline $\begin{array}{l}\text { Schwanen et al. } \\
\text { (2007) }\end{array}$ & $\begin{array}{l}\text { Amsterdam } \\
\text { Utrecht } \\
\text { Netherlands }\end{array}$ & $\begin{array}{l}\text { Place-based } \quad \text { (Cumulative } \\
\text { Opportunities; Minimum time to } \\
\text { transport) }\end{array}$ & $\begin{array}{l}\text { Structural Equation } \\
\text { Modelling }\end{array}$ & $\begin{array}{l}\text { Trip making and } \\
\text { Activity } \\
\text { participation }\end{array}$ & 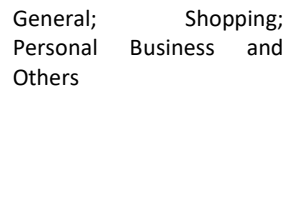 & Auto & $\begin{array}{l}\text { Mixed effect. Accessibility positively influences between-partner } \\
\text { interactions in maintenance activity participation. They suggest that in a } \\
\text { neighbourhood with good accessibility to shops, men may take care of more } \\
\text { household tasks due to fewer space-time constraints. The travel time to } \\
\text { the nearest shopping centre for clothing or footwear suggest that } \\
\text { individuals participate more frequently in shopping for convenience goods } \\
\text { independent of their spouse, as the travel time rises. }\end{array}$ \\
\hline Wu (2012) & $\begin{array}{l}\text { San Francisco, } \\
\text { United States }\end{array}$ & $\begin{array}{l}\text { A mix of Place-based with } \\
\text { Infrastructure-based (Distance } \\
\text { to Transport and Headway). }\end{array}$ & $\begin{array}{l}\text { Multivariate linear } \\
\text { regression }\end{array}$ & Trip making & General & Auto & $\begin{array}{l}\text { Negative effect. Higher levels of walking and public transport accessibility } \\
\text { are associated with fewer trips by car. }\end{array}$ \\
\hline Bhat et al. (2013) & $\begin{array}{l}\text { Los Angeles Region, } \\
\text { United States }\end{array}$ & $\begin{array}{l}\text { Place-based (Cumulative } \\
\text { Opportunities; Gravity-type) }\end{array}$ & $\begin{array}{l}\text { Multiple Discrete } \\
\text { Continuous }\end{array}$ & $\begin{array}{l}\text { Activity } \\
\text { Participation }\end{array}$ & 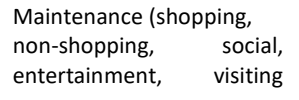 & Auto & Mixed effects. \\
\hline
\end{tabular}


Luz, G., Barboza, M. H. C., Portugal, L., Giannotti, M., van Wee, B. (2022). Does better accessibility help to reduce social exclusion? Evidence from the city of São Paulo, Brazil. Transportation Research Part A: Policy and Practice, 166, 186-217. https://doi.org/10.1016/i.tra.2022.10.005

\begin{tabular}{|c|c|c|c|c|c|c|c|}
\hline Author & Study Area & Accessibility Measure & Method & Study focus & Trip / Activity Purpose & Transport Mode & Findings \\
\hline & & & $\begin{array}{ll}\begin{array}{l}\text { Extreme } \\
\text { (MDCEV) }\end{array} & \text { Value } \\
\end{array}$ & & $\begin{array}{l}\text { friends and family, active } \\
\text { recreation, eat-out, work- } \\
\text { related) }\end{array}$ & & \\
\hline Seo et al. (2013) & Seoul, South Korea & $\begin{array}{l}\text { Utility-based (Logsum) and } \\
\text { Infrastructure-based }\end{array}$ & $\begin{array}{l}\text { Multivariate linear } \\
\text { regression }\end{array}$ & Trip making & $\begin{array}{l}\text { Shopping, personal } \\
\text { business and leisure }\end{array}$ & $\begin{array}{l}\text { Auto and Public } \\
\text { Transit }\end{array}$ & $\begin{array}{l}\text { Mixed effect. Maintenance trips are negatively related to accessibility, } \\
\text { while other purpose trips are positively related. Higher accessibility does } \\
\text { not always lead to more activity participation. }\end{array}$ \\
\hline $\begin{array}{l}\text { Krasić } \quad \text { and } \\
\text { Novačko (2015) }\end{array}$ & Zagreb, Croatia & $\begin{array}{l}\text { Place-based } \\
\text { (Distance to transport) }\end{array}$ & $\begin{array}{l}\text { Multivariate linear } \\
\text { regression (MLR) }\end{array}$ & Trip making & General & $\begin{array}{l}\text { Auto and Public } \\
\text { transport }\end{array}$ & Positive effect \\
\hline Merlin (2015) & United States & $\begin{array}{l}\text { Place-based (Household and Job } \\
\text { density) }\end{array}$ & $\begin{array}{l}\text { Negative Binomial } \\
\text { Regression }\end{array}$ & $\begin{array}{l}\text { Activity } \\
\text { Participation }\end{array}$ & Non-work activities & All travel modes & $\begin{array}{l}\text { Positive effect. Greater residential and employment densities have a } \\
\text { sizeable effect on levels of household non-work activity, with the most } \\
\text { significant influence on households with the fewest vehicles. }\end{array}$ \\
\hline Ding et al. (2016) & Beijing, China & $\begin{array}{l}\text { Space-time (Aggregated utility } \\
\text { of opportunities) }\end{array}$ & $\begin{array}{l}\text { Logit and } \\
\text { Multivariate Linear } \\
\text { Regression }\end{array}$ & $\begin{array}{l}\text { Activity } \\
\text { Participation }\end{array}$ & Shopping & Auto & $\begin{array}{l}\text { Positive effect. Greater person-based accessibility positively affects the } \\
\text { frequency and duration of shopping activity participation. }\end{array}$ \\
\hline $\begin{array}{l}\text { Cordera et al. } \\
\text { (2017) }\end{array}$ & Santander, Spain & $\begin{array}{l}\text { Place-based (Gravity-type; Time } \\
\text { to CBD) }\end{array}$ & $\begin{array}{l}\text { Multivariate linear } \\
\text { regression, Spatial } \\
\text { autoregressive } \\
\text { models, Spatial } \\
\text { autoregressive } \\
\text { models in the error } \\
\text { term, and spatially } \\
\text { filtered Poisson } \\
\text { regression Models }\end{array}$ & Trip making & $\begin{array}{l}\text { Work, Study, Others (Non- } \\
\text { discretionary) }\end{array}$ & $\begin{array}{l}\text { Auto, Motorcycle and } \\
\text { Public Transit }\end{array}$ & $\begin{array}{l}\text { Mixed effect. More accessibility to opportunities decreases trip making in } \\
\text { private vehicles for work purposes, whereas it increases trip production in } \\
\text { other transport modes for non-mandatory purposes. }\end{array}$ \\
\hline $\begin{array}{l}\text { Tian e Ewing } \\
\text { (2017) }\end{array}$ & $\begin{array}{l}\text { Portland, Oregon, } \\
\text { United States }\end{array}$ & $\begin{array}{lr}\text { Place-based } & \text { (Cumulative } \\
\text { Opportunities; } & \text { Minimum } \\
\text { distance to transport) }\end{array}$ & $\begin{array}{l}\text { Zero-Inflated } \\
\text { Negative Binomial } \\
\text { Regression }\end{array}$ & Trip making & General & Walk & $\begin{array}{l}\text { Positive effect. Transit stop density and employment accessibility are good } \\
\text { predictors of the number of walk trips. }\end{array}$ \\
\hline $\begin{array}{l}\text { Wang and Cao } \\
\text { (2017) }\end{array}$ & Hong Kong, China & Place-based (Gravity-type) & $\begin{array}{l}\text { Propensity } \\
\text { Score Match }\end{array}$ & Trip making & General & All travel modes & No effect. \\
\hline $\begin{array}{l}\text { Kroger et al. } \\
(2018)\end{array}$ & Germany & Place-based (Minimum time) & $\begin{array}{l}\text { Linear regression } \\
\text { and Logit }\end{array}$ & Trip making & $\begin{array}{l}\text { Mandatory (Work) and } \\
\text { Discretionary (Shopping) }\end{array}$ & Auto & $\begin{array}{l}\text { Mixed effect. Accessibility to the nearest business district positively impacts } \\
\text { home-based shopping trips but not home-based work trips. }\end{array}$ \\
\hline $\begin{array}{l}\text { Fransen et al. } \\
\text { (2018) }\end{array}$ & $\begin{array}{ll}\text { Wasatch } & \text { Front } \\
\text { region, } & \text { Utah, } \\
\text { United States } & \end{array}$ & $\begin{array}{l}\text { Spatial-temporal (Possible } \\
\text { activity duration) and Place- } \\
\text { based (Gravity-type) }\end{array}$ & $\begin{array}{l}\text { Zero-Inflated } \\
\text { Negative Binomial } \\
\text { Regression }\end{array}$ & $\begin{array}{l}\text { Activity } \\
\text { Participation }\end{array}$ & $\begin{array}{l}\text { Discretionary } \quad \text { (Exercise, } \\
\text { Having a Meal, Personal } \\
\text { Business, Rerigious, } \\
\text { Shopping, Social, Leisure, } \\
\text { Others) }\end{array}$ & Auto & $\begin{array}{l}\text { Mixed effect. There is a moderate positive correlation between the spatial- } \\
\text { temporal accessibility measure and participants' surveyed partaking in } \\
\text { discretionary activities. The gravity-type measure shows a negative and } \\
\text { highly significant relationship to activity participation. }\end{array}$ \\
\hline $\begin{array}{l}\text { Lavieri } \\
(2018)\end{array}$ & Great Britain & $\begin{array}{l}\text { Virtual Accessibility and Place- } \\
\text { based (Minimum time) }\end{array}$ & $\begin{array}{l}\text { Structural Equation } \\
\text { Modelling }\end{array}$ & $\begin{array}{l}\text { Activity } \\
\text { Participation }\end{array}$ & $\begin{array}{l}\text { Mandatory } \\
\text { Maintenance, } \\
\text { Discretionary }\end{array}$ & Virtual & $\begin{array}{l}\text { Negative effect. Virtual accessibility reduces both the number and the } \\
\text { duration of work episodes. Virtual accessibility negatively impacts the } \\
\text { number of maintenance activities but does not seem to affect the duration } \\
\text { of out-of-home maintenance activities. Physical accessibility negatively } \\
\text { impacts the number of maintenance activities. Individuals who perceive } \\
\text { ease of access to opportunities tend to concentrate their maintenance } \\
\text { activities in fewer and longer episodes }\end{array}$ \\
\hline $\begin{array}{l}\text { Zhang et al. } \\
\text { (2019) }\end{array}$ & $\begin{array}{l}\text { Portland, Oregon, } \\
\text { United States }\end{array}$ & $\begin{array}{l}\text { Place-based (Household density } \\
\text { and Container measure) }\end{array}$ & $\begin{array}{l}\text { Negative Binomial } \\
\text { Regression }\end{array}$ & Trip making & $\begin{array}{l}\text { General, Mandatory (Work, } \\
\text { Education), shopping, } \\
\text { recreation, and Other }\end{array}$ & All travel modes & $\begin{array}{l}\text { Mixed effect. People who live in denser neighbourhoods are more likely to } \\
\text { make more trips. Workers who live in denser areas will likely generate more } \\
\text { home-based work trips. Higher urban living infrastructure density is } \\
\text { associated with more shopping trips. Household density has a negative } \\
\text { impact on entertainment or social activities. }\end{array}$ \\
\hline
\end{tabular}


Luz, G., Barboza, M. H. C., Portugal, L., Giannotti, M., van Wee, B. (2022). Does better accessibility help to reduce social exclusion? Evidence from the city of São Paulo, Brazil. Transportation Research Part A: Policy and Practice, 166, 186-217. https://doi.org/10.1016/i.tra.2022.10.005

\begin{tabular}{|c|c|c|c|c|c|c|c|}
\hline Author & Study Area & Accessibility Measure & Method & Study focus & Trip / Activity Purpose & Transport Mode & Findings \\
\hline $\begin{array}{lll}\text { Cheng } & \text { et } & \text { al. } \\
\text { (2019) } & & \end{array}$ & Nanjing, China & $\begin{array}{l}\text { Place-based (Jobs density; } \\
\text { Population density) }\end{array}$ & $\begin{array}{l}\text { Structural Equation } \\
\text { Modelling }\end{array}$ & $\begin{array}{l}\text { Trip making and } \\
\text { Activity } \\
\text { participation }\end{array}$ & $\begin{array}{l}\text { Mandatory } \quad \text { (Work, } \\
\text { Education or Bureaucracy), } \\
\text { Maintenance (Shopping, } \\
\text { visiting friends, Seeing a } \\
\text { doctor), and Discretionary }\end{array}$ & $\begin{array}{l}\text { Auto, Motorcycle, } \\
\text { Walk, Public Transit, } \\
\text { Bicycle }\end{array}$ & $\begin{array}{l}\text { Mixed effect for trip making. Population density significantly affects trip } \\
\text { generation, and the employment density variable does not indicate any } \\
\text { substantial effects on trips generation. No significant effect on activity } \\
\text { participation. Population and employment density variables show } \\
\text { insignificant impacts on activity participation. }\end{array}$ \\
\hline $\begin{array}{l}\text { Calvo et al. } \\
(2019)\end{array}$ & Madrid, Spain & $\begin{array}{l}\text { Place-based (Job density; } \\
\text { Container-type) }\end{array}$ & $\begin{array}{l}\text { Geographically } \\
\text { Weighted } \\
\text { Regression }\end{array}$ & Trip making & General & Metro & $\begin{array}{l}\text { Positive effect. The number of daily trips increases with the increase of job } \\
\text { density. The accessibility measure that accounts for the number of } \\
\text { residents at less than } 600 \mathrm{~m} \text { to a metro station is statistically significant only } \\
\text { for suburban zones. }\end{array}$ \\
\hline $\begin{array}{l}\text { Allen e Farber } \\
(2020)\end{array}$ & $\begin{array}{l}\text { Greater Toronto } \\
\text { and Hamilton Area, } \\
\text { Canada }\end{array}$ & Place-based (Gravity-type) & $\begin{array}{l}\text { Negative Binomial } \\
\text { Regression }\end{array}$ & $\begin{array}{l}\text { Activity } \\
\text { Participation }\end{array}$ & General & All travel modes & $\begin{array}{l}\text { Positive effect. Improvements in accessibility by public transport are } \\
\text { associated with people participating in a greater number of daily activities. } \\
\text { Accessibility and activity participation presents a sigmoidal relationship. }\end{array}$ \\
\hline $\begin{array}{l}\text { Masoumi } \\
\text { (2021) }\end{array}$ & $\begin{array}{l}\text { (Cairo, Istanbul, } \\
\text { Tehran), Middle } \\
\text { East and North } \\
\text { Africa }\end{array}$ & $\begin{array}{l}\text { Place-based } \\
\text { (Container measure, } \\
\text { Distance to } \\
\text { activities) }\end{array}$ & $\begin{array}{l}\text { ANOVA and } \\
\text { Weighted Least } \\
\text { Squares }\end{array}$ & Trip making & $\begin{array}{l}\text { Mandatory (work and } \\
\text { study) and non-work }\end{array}$ & All travel modes & $\begin{array}{l}\text { Mixed effect. Higher value of accessibility measured by container measure } \\
\text { is associated with less mandatory trips. Shorter distance to activities is } \\
\text { associated with more mandatory trips. }\end{array}$ \\
\hline
\end{tabular}


Luz, G., Barboza, M. H. C., Portugal, L., Giannotti, M., van Wee, B. (2022). Does better accessibility help to reduce social exclusion? Evidence from the city of São Paulo, Brazil. Transportation Research Part A: Policy and Practice, 166, 186-217. https://doi.org/10.1016/i.tra.2022.10.005

\section{Appendix B: Activity Participation models before IV}

Table B - Total activities participation model before the introduction of the IV

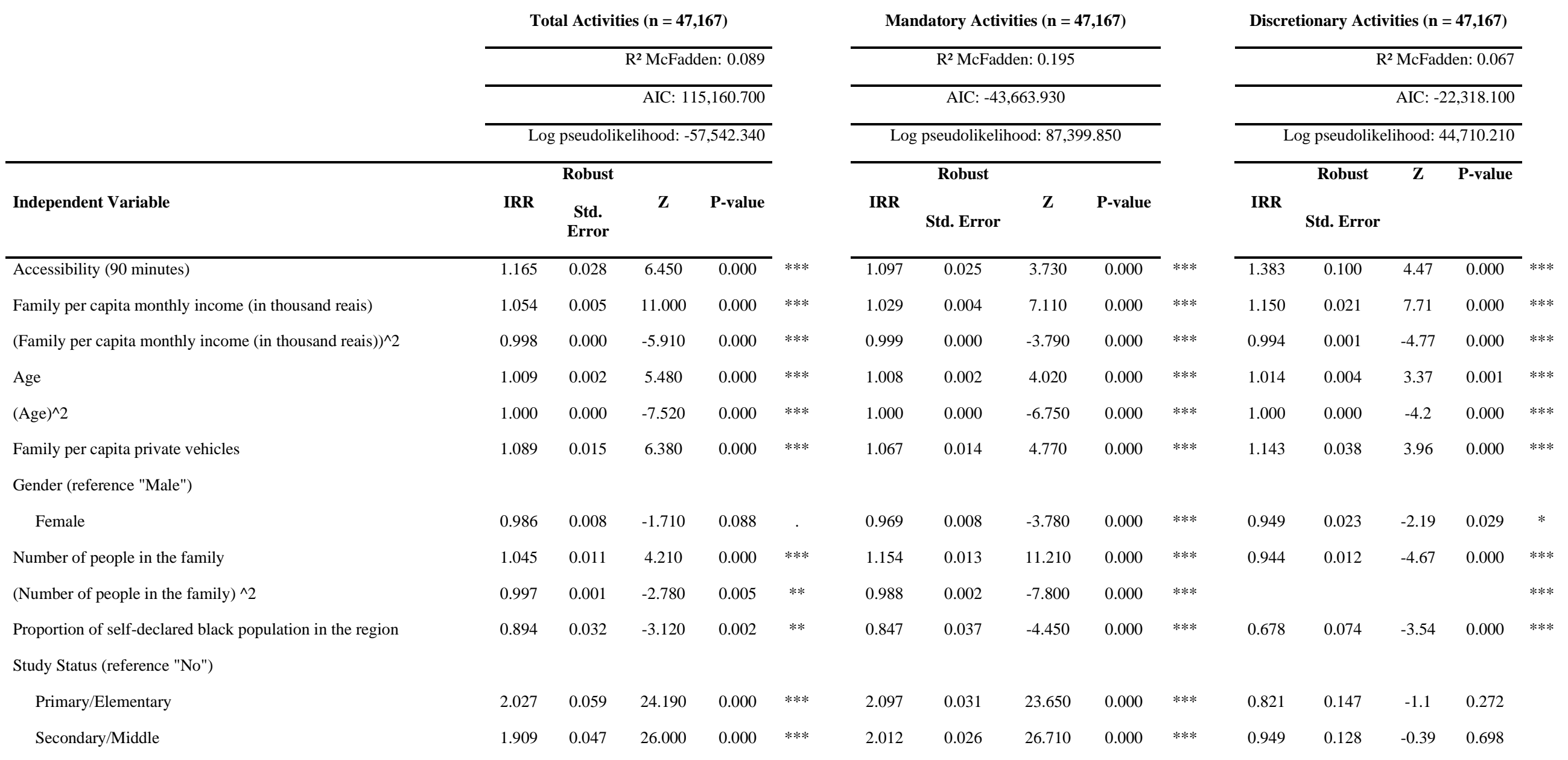


Luz, G., Barboza, M. H. C., Portugal, L., Giannotti, M., van Wee, B. (2022). Does better accessibility help to reduce social exclusion? Evidence from the city of São Paulo, Brazil. Transportation Research Part A: Policy and Practice, 166, 186-217. https://doi.org/10.1016/i.tra.2022.10.005

\section{Other}

Higher/University

Employment status (reference "Has a regular job")

Does odd-jobs
On sick leave
Retired/Pensioner
Unemployed
Never worked
Housewife
Student

Live in a high social vulnerability region (reference "No")

$$
\text { Yes }
$$

Level of Education (reference "Higher Education Complete")

$$
\text { Non-Literate/Incomplete Primary }
$$

Elementary I Complete/Incomplete Elementary II

Elementary II Complete/High School Incomplete

High School Complete / Higher Education Incomplete

Individual income (reference "Did not answer")

$$
\text { Yes }
$$

No

\section{Populational Density}

Family status (reference "Responsible person")

\begin{tabular}{|c|c|c|c|c|c|c|c|c|c|c|c|c|c|c|}
\hline 1.508 & 0.021 & 28.920 & 0.000 & $* * *$ & 1.643 & 0.014 & 36.050 & 0.000 & $* * *$ & 0.882 & 0.056 & -1.98 & 0.047 & $*$ \\
\hline 1.424 & 0.042 & 12.100 & 0.000 & $* * *$ & 1.504 & 0.030 & 13.560 & 0.000 & $* * *$ & 1.089 & 0.108 & 0.86 & 0.391 & \\
\hline 0.753 & 0.016 & -13.370 & 0.000 & $* * *$ & 0.632 & 0.025 & -18.350 & 0.000 & $* * *$ & 0.988 & 0.061 & -0.2 & 0.844 & \\
\hline 0.335 & 0.030 & -12.100 & 0.000 & $* * *$ & 0.100 & 0.212 & -10.850 & 0.000 & $* * *$ & 0.719 & 0.122 & -1.94 & 0.053 & . \\
\hline 0.529 & 0.011 & -30.510 & 0.000 & $* * *$ & 0.070 & 0.072 & -36.800 & 0.000 & $* * *$ & 1.513 & 0.056 & 11.13 & 0.000 & $* * *$ \\
\hline 0.499 & 0.014 & -24.660 & 0.000 & $* * *$ & 0.220 & 0.038 & -39.700 & 0.000 & $* * *$ & 1.337 & 0.086 & 4.53 & 0.000 & $* * *$ \\
\hline 0.284 & 0.041 & -8.770 & 0.000 & $* * *$ & 0.072 & 0.338 & -7.770 & 0.000 & $* * *$ & 0.925 & 0.262 & -0.28 & 0.783 & \\
\hline 0.575 & 0.018 & -17.230 & 0.000 & $* * *$ & 0.279 & 0.047 & -27.070 & 0.000 & $* * *$ & 1.648 & 0.108 & 7.63 & 0.000 & $* * *$ \\
\hline 0.641 & 0.016 & -18.070 & 0.000 & $* * *$ & 0.530 & 0.016 & -40.210 & 0.000 & $* * *$ & 0.879 & 0.094 & -1.2 & 0.230 & \\
\hline 0.937 & 0.014 & -4.250 & 0.000 & $* * *$ & 0.939 & 0.016 & -3.920 & 0.000 & $* * *$ & 0.761 & 0.047 & -4.42 & 0.000 & $* * *$ \\
\hline 0.719 & 0.017 & -13.690 & 0.000 & $* * *$ & 0.840 & 0.028 & -6.180 & 0.000 & $* * *$ & 0.573 & 0.038 & -8.31 & 0.000 & $* * *$ \\
\hline 0.785 & 0.016 & -12.110 & 0.000 & $* * *$ & 0.873 & 0.023 & -6.010 & 0.000 & $* * *$ & 0.647 & 0.036 & -7.75 & 0.000 & $* * *$ \\
\hline 0.806 & 0.014 & -12.160 & 0.000 & $* * *$ & 0.882 & 0.020 & -6.420 & 0.000 & $* * *$ & 0.633 & 0.033 & -8.7 & 0.000 & $* * *$ \\
\hline 0.881 & 0.010 & -11.400 & 0.000 & $* * *$ & 0.932 & 0.011 & -6.140 & 0.000 & $* * *$ & 0.717 & 0.023 & -10.56 & 0.000 & $* * *$ \\
\hline 1.086 & 0.009 & 9.460 & 0.000 & $* * *$ & - & - & - & - & & 1.247 & 0.030 & 9.22 & 0.000 & $* * *$ \\
\hline 0.955 & 0.023 & -1.930 & 0.054 & . & - & - & - & - & & 0.915 & 0.056 & -1.46 & 0.144 & \\
\hline 1.002 & 0.000 & 4.610 & 0.000 & $* * *$ & 1.001 & 0.000 & 3.790 & 0.000 & $* * *$ & 1.002 & 0.001 & 2.19 & 0.029 & $*$ \\
\hline 0.892 & 0.010 & -9.780 & 0.000 & $* * *$ & 0.939 & 0.013 & -5.000 & 0.000 & $* * *$ & 0.812 & 0.025 & -6.88 & 0.000 & $* * *$ \\
\hline 0.831 & 0.012 & -13.030 & 0.000 & $* * *$ & 0.851 & 0.015 & -11.050 & 0.000 & $* * *$ & 0.754 & 0.035 & -6.13 & 0.000 & $* * *$ \\
\hline
\end{tabular}

Spouse / Partner

Child / Stepchild 
Luz, G., Barboza, M. H. C., Portugal, L., Giannotti, M., van Wee, B. (2022). Does better accessibility help to reduce social exclusion? Evidence from the city of São Paulo, Brazil. Transportation Research Part A: Policy and Practice, 166, 186-217. https://doi.org/10.1016/i.tra.2022.10.005

\begin{tabular}{|c|c|c|c|c|c|c|c|c|c|c|c|c|c|c|c|}
\hline Other Relative & 0.737 & 0.014 & -16.160 & 0.000 & $* * *$ & 0.840 & 0.019 & -9.190 & 0.000 & $* * *$ & 0.584 & 0.034 & -9.3 & 0.000 & $* * *$ \\
\hline Other Resident & 0.884 & 0.031 & -3.520 & 0.000 & $* * *$ & 0.877 & 0.030 & -4.430 & 0.000 & $* * *$ & 1.050 & 0.105 & 0.49 & 0.622 & \\
\hline Resident Employee & 0.290 & 0.031 & -11.640 & 0.000 & $* * *$ & 0.083 & 0.263 & -9.500 & 0.000 & $* * *$ & 0.896 & 0.138 & -0.71 & 0.477 & \\
\hline Relative of Resident Employee & 0.494 & 0.214 & -1.630 & 0.103 & & 0.677 & 0.352 & -1.110 & 0.268 & & 0.000 & 0.000 & -26.1 & 0.000 & $* * *$ \\
\hline ving with a dependent child (under 18 years old) & 1.281 & 0.014 & 22.740 & 0.000 & $* * *$ & 1.305 & 0.011 & 24.110 & 0.000 & $* * *$ & 1.068 & 0.036 & 1.96 & 0.050 & . \\
\hline ving with a dependent elderly person (over 65 years old) & 1.014 & 0.013 & 1.080 & 0.279 & & 0.956 & 0.013 & -3.360 & 0.001 & $* * *$ & 1.159 & 0.043 & 3.97 & 0.000 & $* * *$ \\
\hline onstant & 0.933 & 0.046 & -1.420 & 0.157 & & 0.725 & 0.056 & -5.740 & 0.000 & $* * *$ & 0.125 & 0.017 & -15.36 & 0.000 & $* * *$ \\
\hline
\end{tabular}

Note: (.) $p<0.1 ;(*) p<0.05 ;(* *) p<0.01 ;(* * *) p<0.001$ 
Luz, G., Barboza, M. H. C., Portugal, L., Giannotti, M., van Wee, B. (2022). Does better accessibility help to reduce social exclusion? Evidence from the city of São Paulo, Brazil. Transportation Research Part A: Policy and Practice, 166, 186-217. https://doi.org/10.1016/i.tra.2022.10.005 